ArTículo

\title{
Variación dialectal y diacrónica del objeto pronominal en wichí/weenhayek (mataguaya): paradigmas prefijante y sufijante
}

\section{Dialectal and diachronic variation of the pronominal object in Wichi/Weenhayek (Mataguayan): prefixing and suffixing paradigms}

Verónica Nercesian

Universidad de Buenos Aires

Consejo Nacional de Investigaciones Científicas y Técnicas vnercesian@conicet.gov.ar

Original recibido: $2018 / 10 / 16$ Dictamen enviado al autor: 2019/05/24 Aceptado: 2019/09/10

\section{Abstract}

Based on primary data and secondary sources, this paper analyzes the diatopic and diachronic variation of the pronominal object, which distinguishes the Pilcomayeño and Bermejeño dialectal groups in Wichi/Weenhayek language (Mataguayan family, Argentina and Estado Plurinacional de Bolivia). Whereas the Pilcomayeño dialect employs a prefix in non-derived and causative-derived predicates, and a suffix, in predicates derived by locatives/directionals, the Bermejeño dialect employs a suffix in all syntactic contexts. We argue that the development of the prefixing object in the Pilcomayeño follows the typological correlation to the $\mathrm{VO}$ word order, and develops from a change of lexeme>grammatical morpheme. In a different way, the suffixing paradigm in predicates with 
locatives/directionals in both dialectal groups mirrors the old word order in the asymmetrical serial verb construction and develops from a reanalysis of this construction. This reanalysis leads, also, the grammaticalization of the locatives and directionals from verbal roots. Syntactic cognates in the language family lead us to propose the hypothesis that this syntactic reanalysis could at least have started in the Proto-Mataguayan. Finally, we argue that the Bermejeño dialect regularized the object paradigm to suffixes, and thus, separating from the Mataguayan language family and leading the change.

Keywords: syntactic change, object paradigms, variation, Wichi Weenhayek, Mataguayan family

\section{Resumen}

A partir de datos primarios y fuentes secundarias, este artículo analiza la variación diatópica y diacrónica del objeto pronominal que diferencia los grupos dialectales pilcomayeńo y bermejeño en la lengua wichí/weenhayek (familia mataguaya, Argentina y Estado Plurinacional de Bolivia). El primer grupo emplea un prefijo en predicados transitivos básicos y causativizados, y un sufijo, en predicados derivados mediante locativo/direccional, mientras que el bermejeño emplea el objeto sufijante en todos los contextos sintácticos. Se postula que el desarrollo del paradigma prefijante en el pilcomayeño responde a la correlación tipológica con el orden de palabras $\mathrm{VO}$ y emerge de un cambio lexema>morfema gramatical. En otra dirección, el paradigma sufijante en construcciones con locativos/direccionales en ambos grupos dialectales refleja el antiguo orden de palabras y emerge como resultado del reanálisis de las construcciones de verbos seriales asimétricas que conlleva, a su vez, la gramaticalización de los locativos/ direccionales provenientes de antiguas raíces verbales. Según los cognados sintácticos en la familia, se sugiere la hipótesis de que este reanálisis podría haberse originado incluso desde el proto-mataguayo. Finalmente, se postula que el grupo bermejeño regularizó el paradigma completo de objeto sufijante, lo que lo aleja del tronco mataguayo y lo coloca como grupo innovador. 
Palabras clave: cambio sintáctico, paradigmas de objeto, variación, wichí weenhayek, familia mataguaya

\section{INTRODUCCIÓN}

La variación dialectal de la lengua wichí/weenhayek ${ }^{1}$ (mataguaya) según la localización geográfica de los grupos se documentó, al menos, desde la segunda mitad del siglo XIx. Sin embargo, aún no existe un escenario claro de las agrupaciones dialectales, ni de los rasgos de variación, lo que explica las discrepancias acerca del número y delimitación de variedades en la bibliografía.

A modo de recapitulación, en el siglo xIx, Samuel A. Lafone Quevedo $(1895$; 1896a; 1896b; 1897) reconoció cuatro variedades: 1$)$ Nocten -según apuntes de Massei-, 2) Vejoz -según el MS conservado por d'Orbigny-, 3) Mataco -según Remedi- y 4) Mataco -según Pelleschi-. Avanzado el siglo xx, Tovar $(1961 ; 1964)$ distinguió tres dialectos: 1) Vejoz, en la ciudad de Embarcación (Salta); 2) Guisnay, en el este de Salta (Mosconi, Tartagal, Misión La Paz) y oeste de Formosa (El Potrillo), y 3) Nocten en Villamontes, en el Estado Plurinacional de Bolivia. En 1968, Elena Najlis señaló las discrepancias que ya existían para la época respecto a las variedades y reconoció cinco: 1) los vejoces, en

1 Wichí 'gente' también refiere a la lengua. Los grupos bolivianos se autodenominan wikyi weenhayek o simplemente weenhayek 'gente diferente'. El término mataco, usado en el pasado para nombrar a este pueblo, fue reemplazado por el término nativo wichí por los propios hablantes. 
el límite oeste; 2) los noctenes, en el norte, extremo oeste; 3) los guisnais, en el norte, parte central y este; 4) los montaraces, en la zona entre los dos ríos, y 5) los matacos a secas en el sur de la región. Golluscio (1993a; 1993b) sumó el "dialecto del Teuco" y observa que este debería ser una cuarta variedad no considerada en la clasificación de Tovar. Comparando las consonantes palatales, velares y uvulares, y las eyectivas, Gerzenstein (1992; 2003) distinguió tres grupos: 1) el wichí boliviano (weenhayek), según Cleasson (1994), 2) el wichí salteño, según Viñas Urquiza (1974), y 3) el wichí oriental en el río Bermejo, subdividido en arribeños y abajeños, según sus propios datos.

El estudio de la variación dialectal que llevo adelante revela que ciertas diferencias morfosintácticas, como el sistema pronominal verbal, fortalece la división en dos complejos dialectales con mayor tiempo de divergencia: el pilcomayeño y el bermejeño -según la ubicación histórica de los grupos en relación a los ríos Pilcomayo y Bermejo, y la autoidentificación- (cf. Nercesian 2013). Estos grupos no son homogéneos, al interior se observa una subdivisión en arribeños y abajeños. Su distribución geográfica puede verse en el Mapa 1.

El estudio de la variación y el cambio en el sistema pronominal verbal de la lengua aportó evidencias de que el pilcomayeño se encuentra lingüísticamente (y geográficamente) más próximo al tronco mataguayo -lenguas chorote, maká y nivaĉle, además del wichí- que el bermejeño, pero este último más próximo al centro chaqueño. La variación morfosintáctica más relevante entre ambos grupos dialectales es la posición del objeto pronominal en la estructura morfológica del verbo. En el pilcomayeño, es un prefijo en predicados transitivos básicos y deriva- 


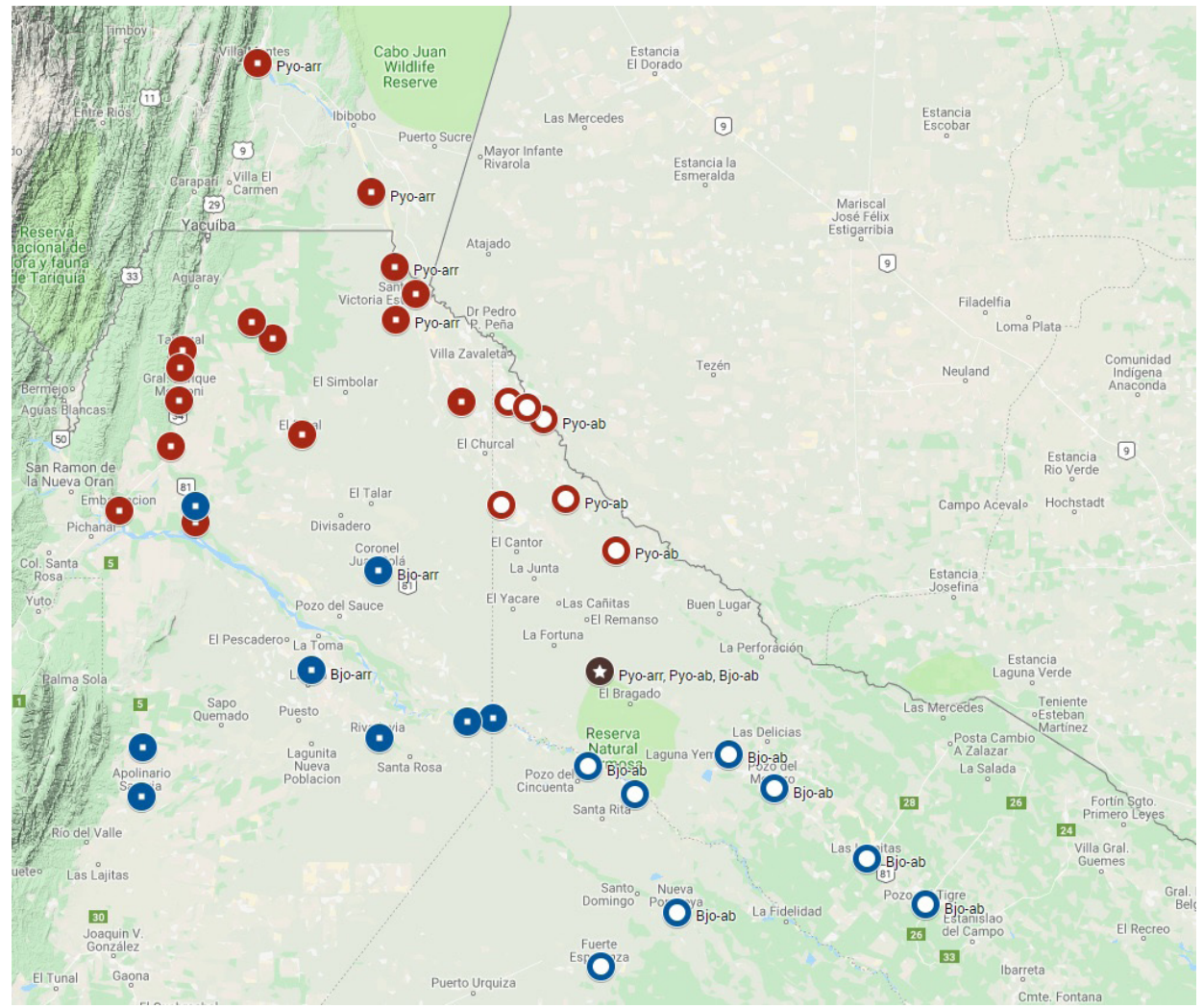

Mapa 1. Distribución de variedades en torno a las principales localidades: pilcomayeño (rojo), bermejeño (azul), pilcomayeño y bermejeño (marrón)

dos mediante causativo, y un sufijo, en predicados con (aplicativo) locativo/direccional, mientras que en el bermejeño, el objeto es un sufijo en todos esos contextos.

La variación en la primera persona sujeto, $o-$ y $n^{\prime}-$, fue mencionada anteriormente (cf. Messineo \& Braunstein 1990), pero nada se había dicho acerca de la variación en la posición del objeto en la estructu- 
ra morfológica del verbo. Tampoco se analizó el desarrollo del paradigma sufijante. Esta diferencia dialectal constituye un rasgo de divergencia muy importante y un indicio de que el desarrollo de los afijos de objeto no fue homogéneo, ni entre variedades ni dentro de una misma variedad.

En este trabajo se analiza esta variación en las dimensiones de espacio y tiempo. A partir de fuentes secundarias de períodos anteriores y actuales se estudia la distribución de las variantes de objeto pronominal en distintas etapas. Sostenemos que el paradigma sufijante surge como resultado del reanálisis de las construcciones de verbos seriados, un proceso mediante el cual una determinada construcción es reinterpretada por los hablantes como un nuevo tipo de construcción (Gildea 2002: 317318). Este proceso es encubierto (no es inmediato), crea polisemia (los morfemas asumen un nuevo significado/función, pero mantienen su significado/función original) y afecta a la construcción entera (no cambia un solo elemento, sino además otros relacionados en la misma construcción). Asimismo, a la luz de cognados morfosintácticos en la familia lingüística, sugerimos que este proceso de reanálisis que dio lugar al paradigma sufijante se difundió en toda la familia. La variedad bermejeña, regularizó el sistema hacia la sufijación.

En la sección $\$ 2$ se describen las fuentes consultadas en este estudio, y en $\$ 3$, se describe el sistema de marcación del objeto en el wichí/weenhayek contemporáneo. En \$4, se analiza el desarrollo del objeto prefijante según las fuentes de cada zona en distintos períodos, y en $\$ 4.5$ se estudia la correlación con el orden de palabras. En $\$ 5$ se examina el desarrollo del paradigma sufijante, se discute la hipótesis de reanálisis y se proponen las etapas evolutivas. Finalmente, en $\$ 6$ se presentan las conclusiones. 


\section{Fuentes}

Este estudio se llevó a cabo con datos recogidos en terreno y de fuentes secundarias. La documentación más antigua, hasta el momento, pertenece a la segunda mitad del siglo xix, publicada en el Boletín Geográfico Argentino bajo la coordinación comentada de Samuel Lafone Quevedo. ${ }^{2}$

Una de las primeras publicaciones de esta serie es la obra del padre Inocencio Massei (1895) sobre la variedad entonces denominada nocten, en el Departamento de Tarija, Estado Plurinacional de Bolivia. Una segunda contribución a la mencionada serie es el manuscrito anónimo sobre la variedad entonces llamada vejoz que el naturalista d'Orbigny (1896) conservó y publicó. Otra publicación del mismo período es la del padre Joaquín Remedi (1896), misionero franciscano del Colegio Apostólico de Salta sobre la variedad denominada mataco, en la provincia de Salta, zona alta del río Bermejo. El registro de la variedad llamada matacos del viajero Giovanni Pelleschi (1897) es otra publicación de esta serie, cuyo antecedente es el registro etnográfico y lingüístico durante el recorrido del Bermejo río arriba (Pelleschi 1886).

La documentación de la primera mitad del siglo xx es todavía más escasa que la del xix. El vocabulario chorote de Robert Lehmann-Nitsche (1910-1911) contiene correspondencias en wichí según sus propios registros en San Pedro de Jujuy en 1906, los de Salvador Debenedetti en Ledesma (provincia de Jujuy) en 1909, y Pelleschi, Remedi, Mas-

2 Recientemente, he hallado un manuscrito del siglo XviII con algunas notas sobre el weenhayek. Apenas he iniciado el análisis de este material, por este motivo no fue incluido aquí. 
sei y d'Orbigny antes mencionados. La obra del padre Richard Hunt $(1913 ; 1936 ; 1940)$ de la South American Missionary Society corresponde a la variedad denominada vejoz o aiyo en la zona de Embarcación (Salta, Argentina), donde se asentaba la Misión Algarrobal desde 1915 y convergían familias de diferentes zonas y dialectos. Las breves notas de Harrington (1948), lamentablemente no mencionan la procedencia de los datos, pero por su similitud con los de Hunt, inferimos que pertenecen a la misma variedad.

Las fuentes de la segunda mitad del siglo xx se incrementan con respecto al período anterior y adquieren especificidad científica. Una comparación de los dialectos wichí, centrada en aspectos fonológicos y léxicos según las fuentes del siglo pasado, es la de Najlis (1968). El estudio gramatical de María Teresa Viñas Urquiza (1974) fue realizado en Misión Chaqueña, ciudad de Embarcación, provincia de Salta, Argentina. Lucía Golluscio (1980a; 1980b; 1993a; 1993b) documenta la denominada variedad del Teuco, en Sauzalito, provincia del Chaco, Argentina. El análisis fonológico de Kenneth Claesson (1994) y el antropológico-lingüístico de Jan-Ake Alvarsson (1979; 1984) estudian el grupo weenhayek (antes llamados nocten) en Villamontes y la rivera del Pilcomayo boliviana. La gramática con ejercicios del padre Roberto Lunt (1999) retoma el trabajo de Richard Hunt en Embarcación.

En cuanto a las fuentes contemporáneas, el estudio gramatical de Jimena Terraza (2009) en Rivadavia, provincia de Salta, Argentina, corresponde al bermejeño arribeño. El cuadernillo escolar de gramática wichí realizado por Maestros Especiales de Modalidad Aborigen con un Equipo Técnico de la Universidad de Buenos Aires, en el Departamento 
de Ramón Lista, Formosa, Argentina (DIRLi 2003), contiene datos de la variedad pilcomayeña abajeña.

Los datos recogidos en terreno por mí provienen de distintos trabajos de campo desde 2002 en diversas zonas: ARgentina - Comunidades de las localidades de Sauzalito y Nueva Pompeya (provincia de Chaco), Pozo del Tigre, Las Lomitas, J.G. Bazán, Pozo del Mortero, Laguna Yema, Ingeniero Juárez y María Cristina (provincia de Formosa), Tartagal, Alto la Sierra y La Junta (provincia de Salta); ESTAdo PLURINACIONAL DE Bolivia - Comunidades de Villamontes y Crevaux (Departamento de Tarija). Además, realicé talleres de gramática wichí en la localidad de Morillo, provincia de Salta, a los que asistió un grupo de aproximadamente treinta hablantes nativos de comunidades de distintas zonas de Salta, Chaco y Formosa. Esto permitió la constatación de análisis y de datos, y la anotación de nuevos ejemplos.

\section{LA MARCACIÓN DEL OBJETO PRONOMINAL EN WICHÍ/WEENHAYEK CONTEMPORÁNEO}

El sistema de alineamiento en wichí/weenhayek es nominativo-acusativo en la primera y la segunda persona, y neutro en la tercera persona (cero para el sujeto y el objeto). ${ }^{3}$ En los ejemplos (1a-c) y (2a-c), el mismo afi-

3 En algunos estudios, los prefijos $i-\sim h i-\sim y i$-fueron segmentados como tercera persona en algunos verbos, y los prefijos de persona seguidos de $-t(V)$ - como un paradigma distinto de ciertos verbos (cf. Viñas Urquiza 1974; Claesson 1994; Terraza 2009). Sin embargo, a la luz de nuevos datos y de la comparación con otras lenguas mataguayas, hemos mostrado que $t(V)$ - e $i$ - 


\title{
jo pronominal que indica el sujeto de primera persona en un predicado intransitivo se usa en un predicado transitivo, y el objeto es formalmen- te distinto.
}

\author{
(1) Pilcomayeño ${ }^{4}$ \\ a. ot'ischey \\ o-t'ischey \\ 1suJ-reír \\ 'Me río'. (Nercesian 2015, TC Palmarcito, Formosa, Argentina)
}

$(-h i-\sim y i-)$ son históricamente morfemas que distinguen las clases verbales intransitiva agentiva y transitiva, respectivamente (cf. Vidal \& Nercesian 2005b; Nercesian 2014 [2011]; Nercesian \& Vidal 2014; Vidal \& Nercesian, en prensa). Esta distinción de clase verbal parece ser muy antigua, también se encuentra en nivaĉle, en la que residuos de esos prefijos se reanalizaron por completo como marcas de persona. En wichí, actualmente, $t(V)$ - e $i$ - están parcialmente colexicalizados y generalmente fusionados con la raíz, oscureciendo a veces la segmentación, pero activos aún en la derivación causativa (n'-t-katin 'yo salto', Ø-i-katih-yen-n’u él/ella me hace saltar') y en las formas del imperativo en las que estos prefijos desaparecen ( $k a t i n$ 'saltá). Aparecen en otras personas del paradigma: $n$ 't-katin 'yo salto', la-ta-katin 'vos saltás', Ø-takatin 'él/ella salta'; Ø-i-potsin 'él/ella trenza algo', $t$-i-potsin 'nosotros/as trenzamos algo'; y en otra zona geográfica, Tovar (1981: 201) registró casos en los que $i$ - se encuentra en la primera y la segunda persona: $\underline{o} i c h u f w i$ 'uno se dirige', donde $o$ - es 1 suj e $i$ - el prefijo en cuestión, lechu?m a chiq a i fwit pej waj 'si te alcanza el agua que llevas', donde el prefijo a-de aifwitpej 'llevas todo el tiempo' es 2suj e $i$ - el prefijo en cuestión. En este trabajo solo hemos segmentado el prefijo cuando fue relevante, en el resto de los casos se segmentó como parte de la raíz.

4 Todos los ejemplos siguen las reglas para glosas de Leipzig con cuatro líneas. Sin embargo, en la primera y cuarta líneas se respetó, respectivamente, la transcripción y la traducción de la fuente original. Por consiguiente, en la mayoría de los casos la primera línea contiene la segmentación morfológica y símbolos utilizados a tal fin tal como se encuentran en los ejemplos extraídos de las fuentes. La segunda y la tercera línea es propia o adaptada a las glosas de 
b. oaichufwan

o-a-ichufwan

1suj-2овJ-enseñar

'Yo te enseño'. (Nercesian 2015, TC Palmarcito, Formosa, Argentina)

c. lachufwann'o

la-chufwan-n'o

2suj-enseñar-1овJ

'Vos me enseñás'. (Nercesian 2015, TC Palmarcito, Formosa, Argentina)

(2) Bermejeño

a. n'tischey

n'-t'ischey

1suJ-reír

‘Me río'. (Nercesian 2003, base de datos léxica bermejeño)

b. n'chefwen'am

n'-chefwen-'am

1suj-enseñar-2oвj

'Yo te enseño'. (Nercesian 2003, base de datos léxica bermejeño)

Leipzig. Por tal motivo, cuando hay certeza de la correspondencia actual en la lengua, el análisis propuesto puede presentar alguna diferencia con la de la transcripción original. Diferencias en la segmentación son aclaradas en el texto. 
12 Nercesian, Verónica. 2019. Variación dialectal y diacrónica del objeto pronominal en wichí/weenhayek

c. lachefwenn'u

la-chefwen-n'u

2suj-enseñar-1овј

'Vos me enseñás'. (Nercesian 2003, base de datos léxica bermejeño)

En los ejemplos (3a y b) y (4a y b), la tercera persona sujeto y objeto en predicados intransitivos y transitivos es cero.

(3) Pilcomayeño

a. tischey

t'ischey

3suj.reír

'Él/ella se ríe’. (Nercesian 2015, TC Palmarcito, Formosa, Argentina)

b. ichufwan

ichufwan

3suj.ЗОвј.enseñar

'Él/ella le enseña'. (Nercesian 2015, TC Palmarcito, Formosa, Argentina)

(4) Bermejeño
a. t'ischey
t'ischey
3suj.reír
'Él/ella se ríe'. (Nercesian 2003, base de datos léxica bermejeño) 
b. ichefwen

ichefwen

3suj.enseñar.ЗОвј

'Él/ella le enseña'. (Nercesian 2003, base de datos léxica bermejeño)

En el Cuadro 1, se presenta el paradigma verbal completo del wichí/ weenhayek. Las formas de plural añaden el sufijo de número verbal -hen.

\section{Cuadro 1. Paradigma pronominal de sujeto y objeto}

\begin{tabular}{|c|c|c|c|c|c|}
\hline \multirow{2}{*}{\multicolumn{2}{|c|}{ Persona }} & \multicolumn{2}{|l|}{ Sujeto } & \multicolumn{2}{|l|}{ Objeto } \\
\hline & & \multirow{2}{*}{$\begin{array}{l}\text { Рyo } \\
\text { o-, n'- (ab.) }\end{array}$} & \multirow{2}{*}{$\begin{array}{l}\text { Bjo } \\
\text { n'- }\end{array}$} & \multirow{2}{*}{$\begin{array}{l}\text { Pyo } \\
\text {-n'o }\end{array}$} & \multirow{2}{*}{$\begin{array}{l}\text { Bjo } \\
\text {-n'u }\end{array}$} \\
\hline SG & 1 & & & & \\
\hline & 2 & la- - le-, a- & la-, a- & $a-$, -’am & -'am \\
\hline & 3 & $\varnothing$ & $\varnothing$ & $\varnothing$ & $\varnothing$ \\
\hline \multirow[t]{4}{*}{ PL } & $1 \mathrm{EXCL}$ & o- & n'- & - n'o + -hen & $-n^{\prime} u+-$ hen \\
\hline & $1 \mathrm{INCL}$ & n'a- & to- - ti- & n'a-, -nam + -hen & -nam \\
\hline & 2 & la- - le- & la- & a- + -hen, -'am + -hen & -'am + -hen \\
\hline & 3 & $\varnothing$ & $\varnothing$ & $\varnothing+$-hen & $\varnothing+$-hen \\
\hline
\end{tabular}

* En la comunidad de Palmarcito, Ramón Lista, provincia de Formosa (variedad pilcomayo abajeño) emplean el prefijo n- en lugar de o- en algunos predicados transitivos de manera obligatoria y sin condicionamiento fonológico. Su distribución aún no es del todo clara para mí. Es posible que, en la evolución de las formas no- - nu- hacia o- en el pilcomayeño y n- en el bermejeño, este grupo que preserva las dos variantes haya sido una zona de transición y hoy se encuentren lexicalizados.

La variación sustancial en la marcación de la persona objeto es la posición en la estructura morfológica del verbo. En el pilcomayeño, el prefijo de objeto ocurre con verbos transitivos básicos y causativizados, (5a) 
y (5b) respectivamente, a excepción de la primera persona que siempre es sufijo, como en (5c). Las formas sufijantes de objeto ocurren con raíces verbales derivadas mediante un aplicativo, como en (5d).

(5) Pilcomayeño

a. naiw'en

n-a-iw'en

1suj-2OBJ-ver

'Te veo'. (Nercesian 2015, TC Palmarcito, Formosa, Argentina)

b. naikatahyen

n-a-ikatay-yen

1suJ-2OBJ-cocinar-CAUS

'Te hago cocinar'. (Nercesian 2015, TC Palmarcito, Formosa, Argentina)

c. lachufwann'o

la-chufwan-n'o

2sUj-enseñar-1овJ

'Me enseñás'. (Nercesian 2015, TC Palmarcito, Formosa, Argentina)

d. oyämlhiamho

o-yämlhi-'am-ho

1suJ-hablar-2OBJ-APL.ASOC

'Te hablo a vos'. (Nercesian 2015, TC Palmarcito, Formosa, Argentina) 
En la variedad bermejeña, en cambio, el objeto es un sufijo en todos los contextos: un predicado transitivo básico, en (6a), uno causativizado, en (6b), y uno derivado mediante aplicativo, en (6c).

(6) Bermejeño
a. n'w'en'am
n'-w'en-'am
1suJ-ver-2OBJ
'Te veo'. (Nercesian 2003, base de datos léxica bermejeño)

b. n'katahyen'am

n'-ikatay-yen-'am

1suj-cocinar-CAUs-2OBJ

'Te hago cocinar'. (Nercesian 2003, base de datos léxica bermejeño)

c. n'yomlhiambu

n'-yomlhi-'am-hu

1suJ-hablar-2OBJ-APL.ASOC

'Te hablo a vos'. (Nercesian 2003, base de datos léxica bermejeño)

Nos centraremos particularmente en el análisis de la primera y la segunda persona singular, dado que las formas plurales son formadas mediante los mismos morfemas de singular más el sufijo de plural verbal, excepto el objeto de primera persona plural inclusiva que se expresa mediante el sufijo -nam. De esta última forma contamos con muy poca información en las fuentes antiguas. 
4. El desarrollo del objeto prefijante

\subsection{Segunda mitad del siglo XIX}

En las fuentes de este período se encontraron algunos ejemplos de predicados transitivos, aunque con abundantes vacíos, que permiten ilustrar el funcionamiento del sistema pronominal en la época.

Primera persona objeto. En la traducción del Padre Nuestro al wichí nocten (Massei 1895), se encontró un ejemplo del objeto de primera persona plural en un predicado transitivo básico (7) y con partícula (8). En el ejemplo (7) se observa que, en un predicado imperativo, el objeto de primera persona plural se indicaba mediante el pronombre libre en posición posverbal nosleemel.

(7) Nocten

[...] aaté em' maltej nosleemel nousei

aaté em' maltej nosleem-el no-use-i

como 2PRO IMP.perdonar 1PRO-PL 1POS-pensamiento-PL

taqueziequiegen

ta que-zie-quie-gen

CONJ.R NEG-estar.bien-NEG-PL

'del mismo modo perdónanos tú nuestras malas obras'.

(Massei 1895: 353) 
En un predicado transitivo con partícula, como el de 'ayudar' en (8), el objeto de primera persona plural también se encuentra en posición posverbal, pero como clítico o afijo: no-.

(8) Nocten

Quiotte noyegen noquieuye eñil

quiotte no-ye-gen no-quieu-ye eñi-l

IMP.ayudar 1OBJ-LOC-PL 1sUJ-obedecer-LOC palabra-PL

'Ayúdanos para que cumplamos tus palabras'.

(Massei 1895: 353)

En palabras del autor, noyegen 'a nosotros' es "dativo plural del pronombre personal" (Massei 1895: 355). A la luz de los análisis actuales, esta forma pronominal objetiva está compuesta por más de un morfema: no '1a persona', ye 'partícula locativa', gen 'plural verbal' (actualmente escrito como-hen).

En los registros del manuscrito conservado por d'Orbigny sobre los vejoces no hemos encontrado ejemplos o referencia a las formas objetivas del pronombre.

Sobre el grupo mataco, se encontraron algunos ejemplos en el vocabulario wichí conformado por Lafone Quevedo a partir de las notas del padre Remedi. Uno de esos ejemplos presenta la primera persona objeto en un predicado transitivo básico como 'enseñar'; véase (9). 
(9) Mataco

am-Chujuen-nü

am chufwen-n'u

2PRo enseñar-1OBJ

'Vos me enseñás'. (Lafone Quevedo 1896a: 357)

En el ejemplo (9), el pronombre que expresa el sujeto se encuentra ańadido a la izquierda del verbo y el que indica el objeto de primera persona singular, a la derecha. Al igual que en la documentación del grupo nocten, el objeto de primera persona del predicado transitivo básico se encuentra después del verbo, pero se diferencian en que en el primer caso fue transcripto como un pronombre libre y en el segundo, como ligado. Quizá esta diferencia se deba a que los objetos sean plural y singular, respectivamente, y que en el primer caso además sea un predicado en modo imperativo.

En otra fuente de la variedad mataco (Pelleschi 1897), la primera persona objeto es un sufijo en predicados transitivos básicos, (10), y con la partícula $-y a,(11)$.

(10) Mataco

yaj-lon-nu

yaj-lon-n'u

PROH-matar-1OBJ

'No me mates'. (Pelleschi 1897: 251) 
(11) Mataco

Yaj-a-hemin-nuya? ${ }^{5}$

yaj-a-hemin-nu-ya

PROH-2sUJ-querer/gustar-1OBJ-LOC

‘¿Me quieres?'. (Pelleschi 1897: 251)

El ejemplo (12) es provisto por el autor a los fines de ilustrar la síncopa, y es interesante que el complejo nuya, interpretado como 'a mí' por el autor, se haya transcripto separado, mientras que en (11), se transcribió unido a la base verbal.

Mataco

Yajáémín nuya

yaj-a-hemin nu-ya

PROH-2sUJ-querer/gustar 1OBJ-LOC

‘Vos me querés?'. (Pelleschi 1897: 251)

Tanto en el ejemplo (8) de la variedad nocten, como en el de (12) de la variedad mataco, los complejos no+ye+gen y $n u+y a$ traducidos como 'a nosotros' y 'a mí', respectivamente, se encuentran en posición posverbal pero separados de la raíz y la primera persona, $n o-n u$, interpretada sintácticamente como un objeto, ligada y antepuesta a la partícula ye o ya.

5 El prefijo que hoy se analiza como prohibitivo yaj-, en el siglo xIX también aparece usado en una interrogativa polar. Actualmente, al menos hasta donde me consta, este uso no se atestigua. 
Además, en todos los casos, (8) a (12), el pronombre no nu se transcribió ligado al verbo o a la partícula, pero nunca libre.

Segunda persona objeto. El ejemplo (13) fue hallado en la traducción del Padre Nuestro a la variedad nocten del wichí, y presenta el objeto de segunda persona pospuesto al verbo.

\section{(13) Nocten}

...nisloquen nitajuel em, ninnai em, nitequiu em. nisloquen nitajuel em ninai em nitequiu em todos IMP.conocer 2PRO IMP.amar 2PRO IMP.obedecer 2PRO ...'todos te conozcan, te amen, te hagan caso'.

En el análisis del padre Massei del ejemplo (13), los predicados nitajuel em 'te conozcan', ninnai em 'te amen', nitequiu em 'te hagan caso' son imperativos y el objeto de segunda persona está indicado mediante el pronombre em (variante de am) en posición posverbal. A los fines de aclarar el uso del pronombre, el autor provee un ejemplo de un predicado transitivo en modo indicativo, como el de (14), en cuyo caso la posición del objeto no encuentra diferencias respecto al modo imperativo.

\section{(14) Nocten}

nonnai em

non-nai em

1suj-amar 2PRo

'Te amo'. (Massei 1895: 354) 
La $n$ en coda del prefijo de primera persona no(n)- y de tercera persona imperativo $n i(n)$ - es poco clara para el autor: "parece que debería ser Ninai, con una sola $n$, pero los Indios lo pronuncian con dos" (Massei 1985: 354). ${ }^{6}$ A la luz del conocimiento actual tampoco podemos explicar este fenómeno. Es posible que se deba a una reducción silábica, bastante frecuente en wichí, del tipo ni-nitokw-a [3SUJ.NEG.IRR-mucho-NEG. IRR] > nintokwa 'poco'; to-nitofwelej [sUJ.INDF-conocer] > tontofwelej 'se lo conoce' (Nercesian 2014 [2011]: 117). Es un tipo de reducción que consiste en la elisión de la vocal, lo que, en la resilabificación, resulta en una estructura métrica con una sílaba menos. Si este fuera el caso, la raíz debería ser $n V n a i$. Hemos consultado con algunos hablantes, pero no reconocen el verbo, por lo que también existe la posibilidad de que haya quedado en desuso y sido reemplazado por la raíz yihemen/yihemin 'querer, amar' que es usada actualmente.

La posición posverbal del pronombre libre como objeto en (14) es la misma que la de (7) para la primera persona plural, y que la que suelen ocupar las frases nominales que expresan objetos sintácticos, como en el ejemplo (15).

${ }^{6}$ El prefijo ni-como tercera persona de imperativo hoy está en desuso. Existe un grupo de verbos que inicia con la secuencia $n i$ aparentemente lexicalizada con la base. Para la variedad de los grupos "matacos occidentales del Bermejo", Pelleschi (1897) registra nu-, no-, ni- y n(ante raíz con vocal inicial) como variantes de primera persona sujeto: $n u$-huén 'veo', nu-isset/ nissét 'corto', en donde ni- aparece como resultado de la fusión con la raíz. En Terraza (2009: 192) se analiza un prefijo $n$ - como marcador de voz media, pero los ejemplos que ofrece son solo de tercera persona y la secuencia que queda formada es $n-+i$. Por otro lado, $n i-\ldots-a$ es la negación del modo irrealis para la tercera persona. En suma, el estudio de esta forma en particular aún requiere mayor análisis. 
22 Nercesian, Verónica. 2019. Variación dialectal y diacrónica del objeto pronominal en wichí/weenhayek

(15) Nocten

non nayej Tupa

non nayej Tupa

1suj amar Dios

'Amo a Dios'. (Massei 1895: 354)

Nótese que el autor en ocasiones escribe el mismo clítico pronominal (en este caso el sujeto) unido a la base verbal, como en (14), y separado, como en (15). No estamos en condiciones de afirmar si esta diferencia en la transcripción se trata de una inconsistencia, una forma de presentar el análisis morfológico, o un intento de reflejar una variación de la lengua que muestra una gramaticalización del paradigma pronominal en curso. Por otro lado, Massei realiza una observación sobre las formas nai y nayej: "si yo quiero decir-amo á Dios-se dice-Non nayej Tupa; y si quiero decir-te amo-se dice-Nonnai em." (Massei 1895: 354). Es interesante esta nota porque seńala una diferencia de comportamiento de la partícula según el objeto sea un pronombre o una frase nominal. Este comportamiento también se observa en los datos actuales. El sufijo - ej funciona como un instrumental/compañía/asociativo o como un incoativo, en cualquiera de los casos, cuando el objeto es pronominal, este precede a la partícula (por ejemplo, n'-fwitsaj-'am-ej [1 suJ-ser.malo2OBJ-ASOC] 'Estoy malo/a con vos' (Nercesian 2014 [2011]: 261), pero cuando es una frase nominal, esta está pospuesta al verbo con partícula (por ejemplo, n'-tkhajhay-ej n'-chemet [1suJ-ser.forzudo-INC 1 Pos-trabajo] 'Me hice forzudo/a por mi trabajo' (Nercesian 2014[2011]: 262). 
El ejemplo (16), se extrajo del listado de Lafone Quevedo sobre la documentación del padre Joaquín Remedi. Este muestra, al igual que ejemplos anteriores, el objeto de segunda persona entre la raíz y la partícula locativa $-e$.

(16) Mataco

в-Huoc-on-àme

e-Huoc on-à̉m-e

2Pos-dueño 3suj.gritar-2OBJ-LOC

'Te llama tu patrón'. (Lafone Quevedo 1896a: 357)

En el ejemplo original en (16), los guiones segmentan morfemas y palabras, por eso la segmentación en la segunda línea difiere. Este ejemplo es interesante para observar que, por un lado, al igual que en (8), (11) y (12), el pronombre interpretado como objeto forma un complejo con las partículas ye o ya. En (16), además, se ve con mayor claridad la función derivativa de la partícula unida al pronombre de segunda persona à̉m, el verbo intransitivo 'gritar' deriva en transitivo 'llamar (a gritos) a alguien', tal como ocurre en el wichí contemporáneo. Y, por otro lado, es interesante notar que a diferencia de los ejemplos (8) y (12), en (16), el complejo de pronombre+partícula aparece unido a la base verbal como en (11) y en la actualidad. No obstante, dado que la frase nominal también se transcribió ligada al verbo, no se puede asumir rápidamente que el complejo àme, traducido como 'a vos' por el autor, fuera fonológicamente dependiente para la época. 
En la variedad mataco, Pelleschi (1897) registró el objeto pronominal de segunda persona prefijante en un predicado transitivo básico, como se muestra en (17).
(17) Mataco
Nu-a-ilon-lá
nu-a-ilon-la
1suj-2obJ-matar-FuT
'Te mataré. (Pelleschi 1897: 183)

Este tipo de construcción con objeto de segunda persona prefijante es el que se encuentra actualmente en la variedad pilcomayeña (cf. (1b) y (5)). El recorrido que Pelleschi realizó desde Rivadavia hasta Orán (provincia de Salta, Argentina) atraviesa al menos dos grupos dialectales: uno que vivía en la margen izquierda del río Bermejo hasta el Itiyuro, los llamados vejoces, y otro en la margen derecha del río Bermejo, los Mataguayos (aparentemente, la zona más próxima a Rivadavia). El fray Doroteo Giannecchini del Colegio Misionero en Tarija indica en una carta a Lafone Quevedo:

A fines del siglo pasado, este Colegio de Misioneros fundó en Centa (Oran Argentino) una misión de Mataguayos y Vejoses. Los Mataguayos eran los que ocupaban la margen derecha del río Bermejo, y los Vejoses eran los que ocupaban la izquierda y que llegaban hasta Itiyuru de Caiza: cuyos descendientes esparcidos por el Itiyuru aún ahora se conocen con el simple y general nombre de Matacos del río Seco. 
En este punto del río Seco á pocas leguas fué menester trasladar los Vejoses de la misión de Centa, y por diversas razones fundarles una misión por separado de los Mataguayos, que duró 5 ó 6 años, y que por su volubilidad, fué menester abandonarla, é incorporarla de nuevo á la de los Mataguayos de Centa, de la cual no quedó otra señal que la que tiene aún hoy de "La Reducción” del Seco. (Cita a Giannecchini en Lafone Quevedo 1896b: 127-128).

La convivencia de estos dos grupos en la Misión Franciscana ocurrió mucho antes de que Pelleschi realizara su viaje. No sabemos si los datos del viajero provienen del grupo más próximo a los vejoces o a los mataguayos, puesto que los primeros habían sido trasladados a la zona de los mataguayos. Además, según este registro, los descendientes de los vejoces asumieron el nombre de matacos, tal como los registrara Pelleschi (1897).

En suma, para fines del siglo XIX, ya existía algún uso del objeto de segunda persona como prefijo en la zona próxima al grupo vejoz (pilcomayeńo). El objeto de primera persona singular pareciera encontrarse en un grado de gramaticalización mayor: las formas $n u$ y no ' 1 a persona' presentan reducción fonológica de nuchlam y nojlam, respectivamente, y sin la partícula el pronombre se encuentra ligado a la raíz verbal como sufijo, mientras que el de segunda persona solo presenta reducción fonológica en su forma prefijante: de am se reduce a $a$-, y se observa una variación entre la forma ligada como prefijo -al menos, en el grupo mataco o vejoz; cf. (16) - y la forma libre en posición posverbal al igual que las frases nominales -al menos, en el grupo nocten; cf. (13); este gru- 
po actualmente emplea el prefijo-. Por otro lado, en este mismo período, se observa que la combinación del pronombre con las partículas yala, yele conforman un complejo morfosintáctico en el que, sin importar si está ligado a la base verbal o no, el morfema pronominal es interpretado como un objeto sintáctico y está pospuesto al verbo.

\subsection{La marcación del objeto en la primera mitad del siglo XX}

La documentación de este período está centrada en la Misión Algarrobal en Embarcación, provincia de Salta, Argentina, y realizada por el reverendo Richard Hunt. El misionero se centró en la variedad vejoz, que convivía con otras variedades.

Primera persona. Al igual que en siglo anterior, la primera persona es marcada mediante el enclítico no tanto cuando está seguido de una partícula locativa o direccional como cuando no lo está; véanse ejemplos (18a) y (19a).

(18) Vejoz o Aiyo
a. Le lăn no
b. Ya le lăn
le län no
ya le län
2suj matar 1овj
1овj 2suj matar
'Thou killest me'.
'Thou killest me'.
['Vos me matás', trad. mía]
['Vos me matás', trad. mía]

(Hunt 1940: 88) 
(19) Vejoz o Aiyo
a. Le tăn no ye
b. Le tăn yam e
le tän no ye
le tän yam e
2suj gritar 1OBJ LOC
2suJ gritar 1OBJ LOC
'Thou callest me'.
['Vos me llamás', trad. mía]
'Thou callest me'.
['Vos me llamás', trad. mía]

(Hunt 1940: 89)

En los ejemplos (18b) y (19b), el autor registra una forma alternativa de primera persona ya - yam que se corresponde con la libre yam 'yo' y yamel 'nosotros' y que pertenecería a los ámbitos íntimos de la vida familiar. A este pronombre se opone notham 'yo' y nothamel 'nosotros' de cortesía, que es la forma aparentemente tribal usada para propósitos ordinarios o civiles (Hunt 1936: 15). Lo interesante en los ejemplos provistos es el cambio de posición del objeto cuando se usa no y ya sin partícula: en el primer caso se posiciona después de la raíz verbal (ejemplo 18a), y en el segundo, antes que el clítico de sujeto (ejemplo 18b). Este orden OsV no se había registrado antes, ni en fuentes posteriores, por lo que resulta llamativo y no puede explicarse aún. Además, es la única zona en la que se documentó el pronombre yam para la primera persona objeto. El prefijo ya-como primera persona plural inclusiva, en cambio, se registra actualmente (casi de manera residual) en las distintas zonas de habla wichí. Ambas formas podrían estar históricamente relacionadas.

Ahora bien, sin importar si el pronombre es no o ya, cuando las formas pronominales están seguidas de las partículas locativas y direcciona- 
les (cf. (19a) y (19b)), estas se encuentran en posición posverbal, y son interpretadas como objetos.

Harrington (1948) no brinda ejemplos, pero cita el sufijo -no como objeto de primera persona (p. 28), lo que coincide con los registros del nocten y el vejoz.

Segunda persona. La segunda persona objeto que registra Hunt (1913; $1936 ; 1940)$ es la forma am entre la raíz y cualquiera de las partículas 'E, YE, YEJ, HO, CHE and others with special signification" (1940: 86), como se muestra en (20) y (21).

(20) Vejoz o Aiyo

o-chot-am-e

o-chot-am-e

1suj-ayudar-2OBJ-LOC

'I help thee'. ['Te ayudo', trad. mía] (Hunt 1940: 86)

(21) Vejoz o Aiyo

$O$ tu am che

o tu am che

1sUJ mirar 2OBJ DIR

'I seek thee'. ['Te busco', trad. mía] (Hunt 1940: 87)

Cabe llamar la atención acerca de la diferencia entre (20), donde los morfemas se presentan como ligados, y (21), donde se presentan como morfemas libres. Es muy probable que esta variación del autor no sea 
sino la vacilación respecto de qué tipo de morfema se trataba, pero no podemos afirmarlo. Además, lamentablemente, en el material no se encuentran ejemplos de objeto de segunda persona con verbos transitivos básicos que brinden mayor información acerca de la posición de este morfema en este período y en este grupo dialectal. Una forma similar a la de (20), registró Harrington (1948: 28) para la segunda persona objeto: -ame.

\subsection{La marcación del objeto en la segunda mitad del siglo XX}

En este período, los registros vuelven a ser lo suficientemente diversos como para representar en alguna medida las diferencias diatópicas.

Primera persona. La descripción fonológica de la variedad nocten, o para esta época denominada 'weenhayek, en Villamontes, Estado Plurinacional de Bolivia, provee algunos ejemplos gramaticales (cf. Claesson 1994). En (22), un predicado transitivo básico, y en (23), un predicado derivado, la primera persona objeto singular es un sufijo. Lo documentado por Alvarsson (1984) en la misma zona no difiere.

(22) Weenhayek

la+buumin+?no?

la-huumin-?no?

2suj-querer/amar-1овj

'You like me'. ['Vos me querés/amás', trad. mía] (Claesson 1994: 11) 
(23) Weenhayek

$y i k+{ }^{?}$ nóo $+y e h$

yik-nóo-yeh

3SUJ.ir-1OBJ-ASOC

'(S)he goes for me'. ['Él/ella va por mí', trad. mía] (Claesson 1994: 11)

En Misión Chaqueña, a 45 kilómetros de Embarcación, Viñas Urquiza (1974) registró datos que se asemejan a los del nocten o 'weenhayek. Sus dos colaboradores principales eran de Misión Chaqueña y de Misión Santa María, Departamento de Santa Victoria Este, en la ribera del río Pilcomayo. Según la autora, "si el OD es un pronombre objetivo de 1a o 2a persona, se coloca dentro de la construcción verbal” (1974: 124), tal como se ilustra en el ejemplo (24).

(24) Vejoz

čut-no-ho

chulh-no-ho

IMP.responder-1OBJ-BEN

'Contéstame’. (Viñas Urquiza 1974: 124)

El ejemplo (25), un verbo no derivado con el sufijo de objeto de primera persona fue extraído de uno de los textos interlinearizados por la autora. 
(25) Vejoz

... wok ičahno k’äci.

wok ičah-no k’äci

o 3suj.llevar-1oвj allí

... 'o que me lleve allá.

(Extraído de “Tektas hap tokwah lak’äj”, Viñas Urquiza 1974, T2: 20, línea 80).

En Embarcación, Lunt (1999) registró ejemplos de la variedad denominada "norteña o del río Pilcomayo" -influenciada por el vejoz (Lunt 1999: 7)- que son similares a los de Claesson (1994) y Viñas Urquiza (1974). La primera persona objeto n’o es un sufijo en predicados básicos, (26), y en predicados derivados, (27).

(26) Norteño o del río Pilcomayo

hiw'enn'o

hiw'en-n'o

3suj.ver-10BJ

'Él/ella me ve'. (Lunt 1999: 74)

(27) Norteño o del río Pilcomayo

ifwel n'oho

ifwel n'o-ho

3suJ.contar 1OBJ-BEN

'Me cuenta, me dice'. (Lunt 1999: 74) 
En la zona del Bermejo bajo, Sauzalito, provincia de Chaco, Golluscio (1980b) registró el sufijo -n’u en verbos transitivos con el locativo, direccional o instrumental/compañía/asociativo, como en (28). Estos ejemplos coinciden con los que relevamos actualmente en la misma zona. No encontramos predicados transitivos básicos con el objeto pronominal en los registros de la autora.

(28) Dialecto del Teuco
tsina ichefwen-n'u-yej totonek
tsina ichefwen-n'u-yej to-ton-ek
mujer enseña-1OBJ-ASOC POS.INDEF-gritar/cantar-NMLZ
‘Ella me enseñó esta canción’. (Golluscio 1980b, emisión 201)

Se observa, entonces, que la forma pronominal de objeto de primera persona en este período es, al igual que en la segunda mitad del siglo XIX, posverbal en predicados transitivos básicos y derivados.

Segunda persona. La posición del objeto de segunda persona, también coincide con la actual, pero difiere con algunos registros del siglo XIX.

En este período, la marcación del objeto de segunda persona en la variedad 'weenhayek ya se encuentra gramaticalizada en posición preverbal y después del sujeto, según los registros de Alvarsson (1984), en (29) y Claesson (1994), en (30). 
(29) Weenhayek

o-a-ikyen

'o-a-ikyen

1suJ-2obJ-mandar

'Yo te mando'. (Alvarsson 1984: 34)

(30) Weenhayek

'o+'aa+ya+huminh

'o-'aa-ya-huminh

1sUJ-2OBJ-CL.VBL.TR-querer/amar

'I like you'. ['Yo te quiero/amo', trad. mía] (Claesson 1994: 10)

Cuando el verbo está derivado por un locativo o direccional, el objeto de segunda persona que se encuentra es un sufijo entre la raíz y la partícula; véanse (31) y (32). Verbos como el de (31), t’u(y)e 'cuidar', son raíces actualmente lexicalizadas con el locativo/direccional; sin embargo, el objeto se inserta en medio de la base, manteniendo su posición "original" en la construcción, precediendo el locativo.

(31) Weenhayek

'o-t'u-am-e

'o-t'u-am-e

1suJ-mirar-2OBJ-LOC

'Yo te cuido'. (Alvarsson 1984: 34) 
34 Nercesian, Verónica. 2019. Variación dialectal y diacrónica del objeto pronominal en wichí/weenhayek

(32) Weenhayek

'o+yik+'aam+kye'

'o-yik-'aam-kye'

1sUJ-ir-2OBJ-DIR

'I go with you'. ['Voy con vos (hacia donde estás vos)', trad. mía]

(Claesson 1994: 11)

En el vejoz en Misión Chaqueña, Embarcación (cf. Viñas Urquiza 1974), el objeto de segunda persona es un sufijo en predicados derivados por el locativo o direccional, como se ve en (33). El sufijo -'am de segunda persona se inserta entre la raíz verbal wen 'tener' y el derivativo -ho. Este tipo de construcción es similar a la registrada por Alvarsson (1984) y Claesson (1994) en la zona boliviana.

(33) Vejoz

tik owenamho kalamelos

tik o-wen-'am-ho kalamelos

NEG 1sUJ-tener-2OBJ-BEN caramelos

'No te doy caramelos'. (Viñas Urquiza 1974: 125)

No hemos encontrado mención del objeto de segunda persona en verbos básicos, ni ocurrencias de ese en los textos recogidos por Viñas Urquiza.

Tovar (1981), quien trabajó con hablantes de Embarcación y de San Andrés/Misión La Paz, migrados a Tartagal, registró el objeto de segun- 
da persona en predicados transitivos básicos en posición preverbal, como se muestra en (34).

(34) Vejoz y Pilcomayo (nordeste)

$\begin{array}{lll}0 & a & \text { ilan } \\ 0 & \text { a } & \text { ilän } \\ \text { 1suj } & \text { 2OBJ } & \text { matar } \\ \text { 'Yo te mato'. (Tovar 1981: 200) }\end{array}$

No encontramos referencia respecto de la separación morfológica como palabras independientes, pero es un estilo de anotación en general en su obra. El ejemplo (35) muestra el uso del pronombre de segunda persona como objeto de un predicado derivado por la partícula ho.

(35) Vejoz y Pilcomayo (nordeste)

ta ofwen am ho

ta o-fwen am ho

CONJ.R 1sUJ-decir 2OBJ BEN

'Lo que te dije'. (Tovar 1981: 200)

También en Embarcación, el registro de Lunt (1999) es similar. En el predicado transitivo básico, como en (36), el pronombre es un prefijo, pero en el predicado derivado por el direccional che, en (37), el pronombre es posverbal y no está ligado al verbo, sino a la partícula. 
(36) Norteño o del río Pilcomayo

oaiwom

o-a-iwom

1suJ-2овJ-abandonar

'Yo te abandono'. (Lunt 1999: 77)

(37) Norteño o del río Pilcomayo

itichun amche

itichun am-che

3suJ.pensar 2OBJ-DIR

'Él/ella piensa en ti'. (Lunt 1999: 77)

Los datos de la variedad bermejeña de este período recolectados por Golluscio (1980b) confirman la difusión del objeto de segunda persona pospuesto al verbo en predicados transitivos con locativo/direccional y ligado a este, como se ilustra en (38). Ejemplos o referencia al objeto en verbos transitivos básicos no fueron hallados en el material de la lingüista.

(38) Dialecto del Teuco

$\begin{array}{llll}\text { tsina ha } & \text { tath-ama } & \text { lachinaj toj } \\ \text { tsina ha } & \text { tath-am-a } & \text { lachinaj toj } \\ \text { mujer } & \text { INTERR } & \text { pedir-2OBJ-LOC } & \text { dinero }\end{array}$

‘Ella te pidió dinero?’. (Golluscio 1980b, emisión 195) 
En suma, se observa que en este período más reciente, la variante de objeto prefijante es estable en las variedades que hoy agruparíamos en el complejo dialectal pilcomayeño. Asimismo, se mantiene la forma sufijante de objeto+partícula locativa/direccional en todo el territorio wichí/ weenhayek. No contamos con evidencias del uso sufijante de objeto en predicados transitivos en las variedades que hoy agruparíamos en el complejo dialectal bermejeño, por lo tanto, no podemos asegurar si esta variación ya existía en este período. Especulamos que sí, considerando los registros propios desde 2002 (cf. Vidal \& Nercesian 2005a; 2005b; Nercesian 2007) y fuentes secundarias (cf. Terraza 2009) en los que se documenta el objeto sufijante como variante estable de la prefijante en la variedad pilcomayeña.

\subsection{Sintesis}

El lapso de casi un siglo y medio, parece haber sido el tiempo en que algunas formas pronominales se gramaticalizaron, y este proceso no ocurrió de igual manera en todas las zonas de habla wichí/weenhayek. El Mapa 2, presenta la distribución geográfica de las formas pronominales de objeto de primera y segunda persona según las fuentes del siglo XIX. Nótese la distribución de las variantes del objeto de segunda persona: la forma libre posverbal en la zona del grupo weenhayek en Bolivia, y la prefijante, entre Rivadavia y Orán (Salta, Argentina). Si esta fue la zona de origen del prefijo, considerando la distribución actual (cf. Mapa 5), la difusión se dio hacia el norte y este del territorio wichí/weenhayek. 


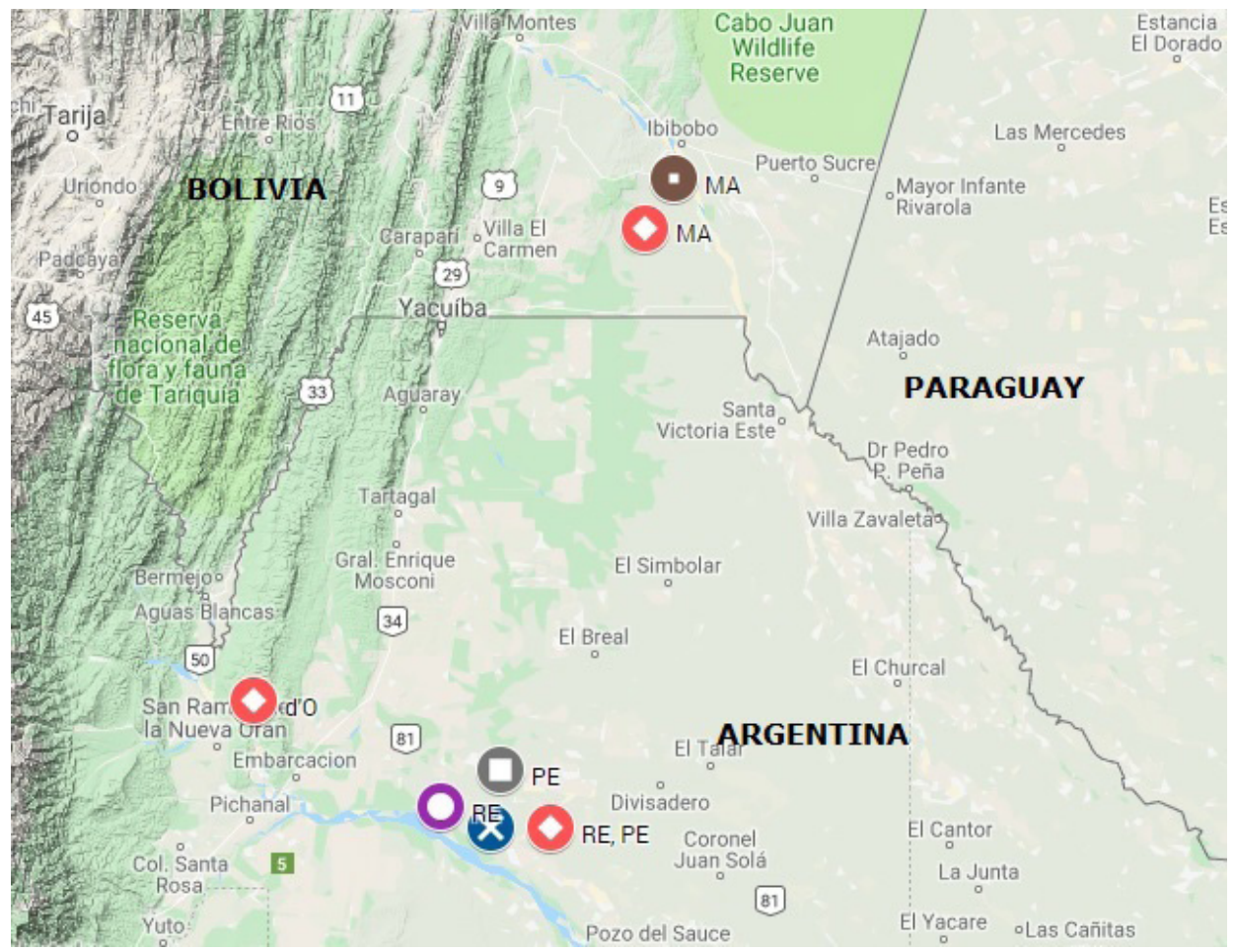

Mapa 2. Segunda mitad del siglo xIx. Distribución del objeto de 1 y 2 persona: 1овј posverbal (azul), 1овј posverbal+partícula (rojo), 2овј preverbal (gris), 2овј posverbal (marrón), 2овј posverbal+partícula (violeta)

El Mapa 3 presenta la geolocalización del objeto de primera y segunda persona según los registros de la primera mitad del siglo xx. Nótese la proximidad geográfica del primer registro del objeto de segunda persona prefijante en el Mapa 1 según fuentes del siglo XIX y los del siglo xx en el Mapa 3.

El Mapa 4 presenta la distribución del objeto de primera y segunda persona según fuentes de la segunda mitad del siglo xx. La localización de 


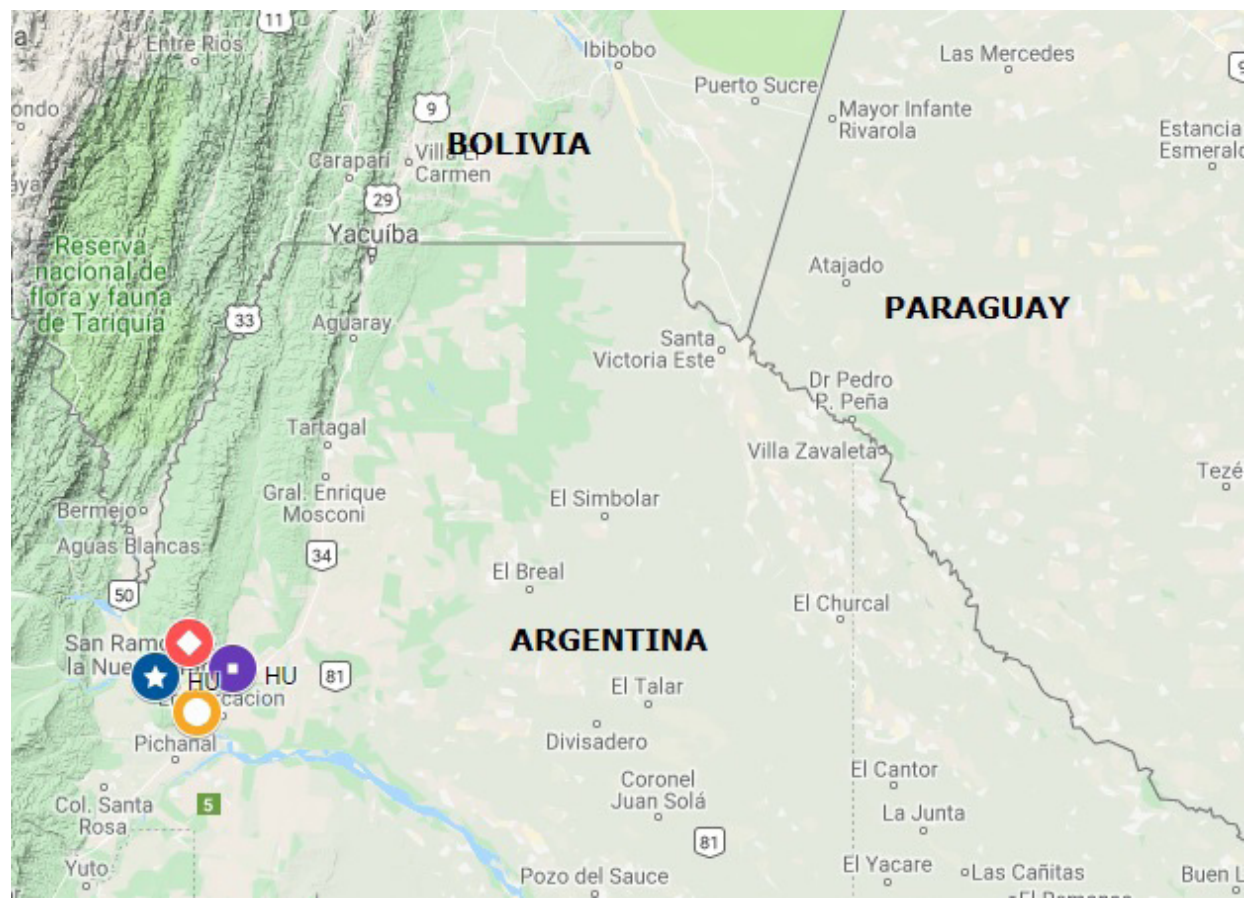

Mapa 3. Primera mitad del siglo xx. Distribución del objeto de $1^{\mathrm{a}}$ y $2^{\mathrm{a}}$ persona: 1овј posverbal (azul), 1овј posverbal+partícula (rojo), 1овј preverbal (amarillo), 2овј posverbal+partícula (violeta)

las variantes prefijante y sufijante del objeto de segunda persona en este período coincide con la que se encuentra en la actualidad (cf. Mapa 5) y confirma su difusión en los grupos del norte del territorio. Mientras que los grupos bermejeños desde Rivadavia (Salta, Argentina) hacia el sudeste asumieron otra dirección.

El Mapa 5 muestra la distribución de las variantes prefijante y sufijante de la segunda persona objeto en la actualidad, según datos propios y de gramáticas del siglo xxi. El objeto de primera persona y el objeto en pre- 


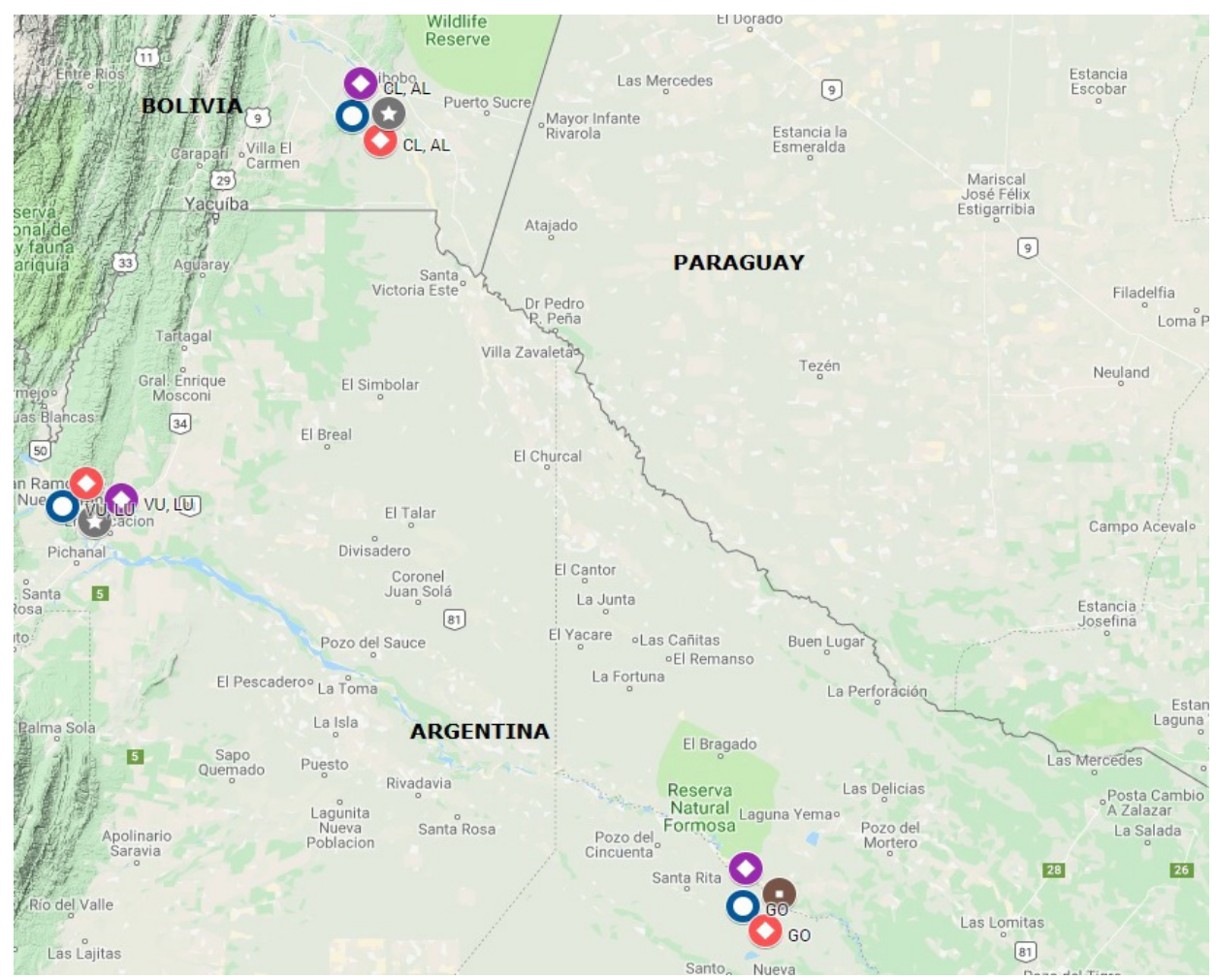

Mapa 4. Segunda mitad del siglo xx. Distribución del objeto de $1^{\mathrm{a}}$ y $2^{\mathrm{a}}$ persona: 1овј posverbal (azul), 1овј posverbal+partícula (rojo), 2овј preverbal (gris), 2овј posverbal (marrón), 2овј posverbal+partícula (violeta)

dicados con locativos, direccionales e instrumental no se indicó, porque en ambos casos se usa el objeto sufijante en todo el territorio. Entonces, la distribución en el Mapa 5 corresponde a la variación en la posición del objeto de segunda persona en predicados no derivados.

El prefijo de objeto, cuyo primer registro en el siglo XIX se encuentra entre Orán y Rivadavia (provincia de Salta), se habría extendido hacia el 


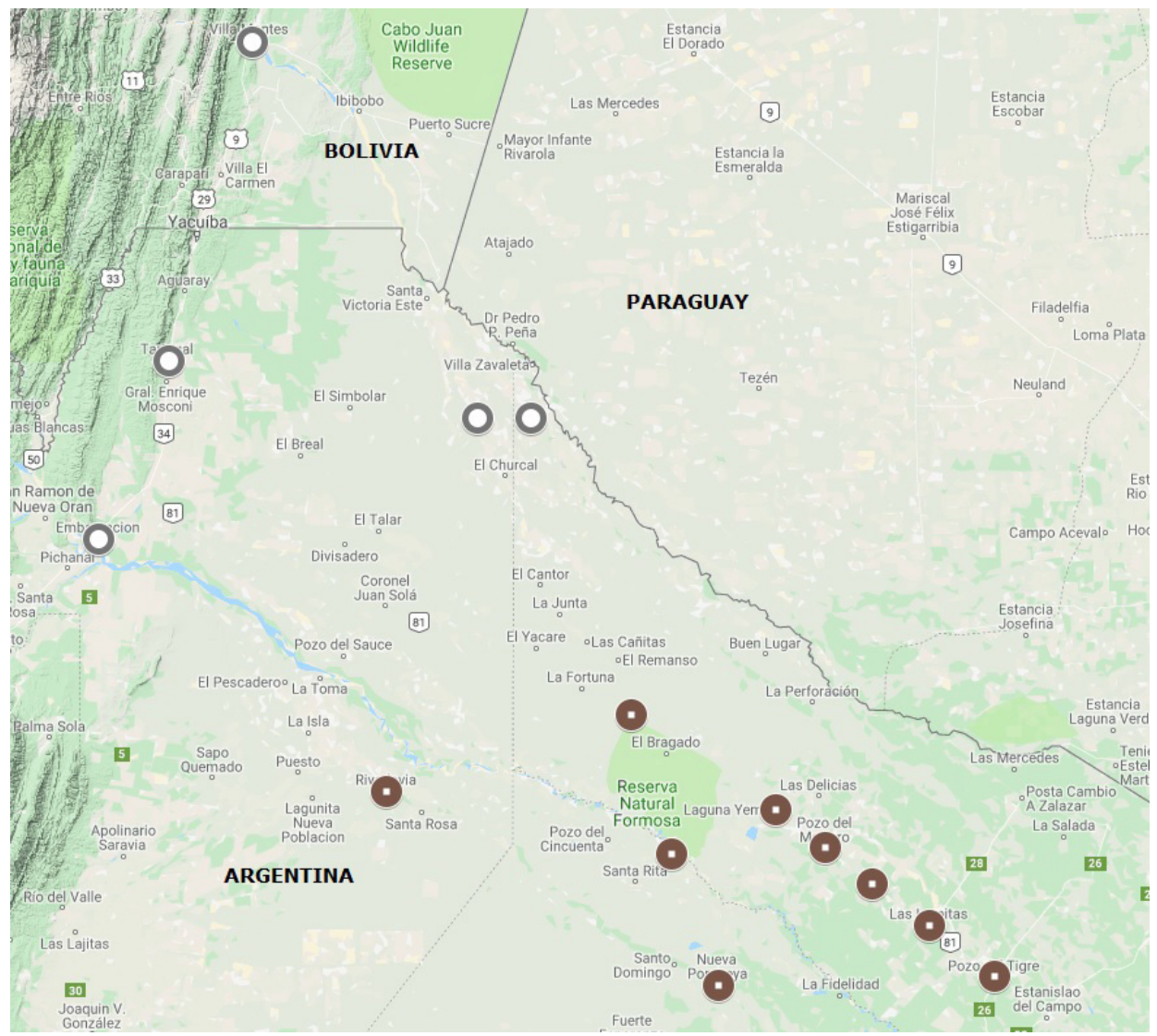

Mapa 5. Distribución del objeto de $2^{\mathrm{a}}$ persona en la actualidad: 2овJ preverbal (gris), 2овJ posverbal (marrón)

norte en el pilcomayeño entre fines de siglo xix y fines de siglo xx. En el bermejeńo, a principios del siglo xxI nuestros propios registros y fuentes secundarias ya registraban la forma sufijante como marca estable. En tanto, el objeto de primera persona singular parece gramaticalizado como sufijo con anterioridad en todo el territorio de habla wichí. 
El desarrollo del sufijo de objeto en predicados básicos y causativizados no solo separa al grupo bermejeńo del pilcomayeño, sino también del resto de las lenguas mataguayas, en las que se encuentra el objeto pronominal prefijante entre el sujeto y la raíz verbal y, en algunos casos, amalgamado con el prefijo de sujeto (cf. Gerzenstein 1994 para el maká; Stell 1987; Fabre 2014; Vidal \& Payne (en prensa) para el nivaĉle; Gerzenstein 1978; Carol 2014 [2012] para el chorote). En este sentido, el grupo wichí pilcomayeño es más próximo al tronco mataguayo que el bermejeño. Queda pendiente el estudio del desarrollo del objeto prefijante en la familia, lo que ayudará a determinar si el grupo pilcomayeño fue innovador en ese proceso o adoptó un proceso de gramaticalización que se venía diseminando en la familia lingüística.

\subsection{La prefijación del objeto y el orden de palabras}

El desarrollo del prefijo cumple las predicciones universales que correlacionan el orden vo con la prefijación, porque se considera que el orden operador-operando (o núcleo-dependiente) en la sintaxis se refleja en la estructura morfológica (cf. Venneman 1973). Considerando a los afijos como núcleos de la construcción, lenguas vo se corresponden con el orden prefijo-raíz. Los universales de Greenberg (1963) postulan que lenguas de orden vso son preposicionales (universal 3), sov son posposicionales (universal 4), y que las que son exclusivamente sufijantes son posposicionales y las exclusivamente prefijantes, preposicionales (universal 27). Esta tendencia se constata empíricamente con los datos del World Atlas of Linguistic Structures (WALS) en línea, correlacionando 
los rasgos 26 "Prefijación vs. Sufijación en la morfología flexiva" (Dryer 2013a) y 83 "Orden de objeto y verbo" (Dryer 2013b). De las lenguas que son fuertemente sufijantes, 269 presentan orden ov y 93 vo, y de las que son fuertemente prefijantes, 6 presentan orden ov y 51 vo. En la misma tendencia, de las que son débilmente sufijantes, 70 son ov y 43 vo, mientras que de las débilmente prefijantes, 23 son ov y 61 son vo.

En wichí/weenhayek contemporáneo, el orden de palabras básico es svo en todas las variedades (por ejemplo, Pilcomayeño, svo: Hay’äj yokwaj sulaj. [tigre morder oso.hormiguero] 'El tigre mordió al oso hormiguero'; Bermejeño, svo: Hay'oj yukwaj selaj. [tigre morder oso.hormiguero] 'El tigre mordió al oso hormiguero'). El orden de palabras vo también se observa en los registros del siglo XIx y principios del xx (por ejemplo, svo: Peiló ilón tzonatáj. [Pedro matar oveja] 'Pedro mató a la oveja' (Mataco, Pelleschi 1897: 261); svo: Aiyăj satkat-hi tsonnataj. [tigre desparramar-Loc oveja] 'El tigre hace desparramo de las ovejas' (Vejoz, Hunt 1913: 86)). Si en algún momento hubo un orden ov, el cambio a vo tuvo que haber sido mucho antes. Pero hasta aquí no hay evidencias de ello.

Sin embargo, las formas sufijantes del objeto (la primera persona del singular aparentemente desarrollada con anterioridad a la segunda mitad del siglo XIX y el paradigma empleado con los locativos y direccionales), no responden a la correlación tipológica entre el orden vo y prefijos. También se ha visto en otras lenguas, por ejemplo, en navajo, lengua atabascana-eyak-tlingit del sudoeste de Estados Unidos, el orden básico de palabras es ov y tiene prefijos pronominales, en lugar de sufijos (Mithun 2003). Esto plantea ciertas restricciones empíricas al desarro- 
llo de paradigmas prefijantes según la correlación tipológica vo, y sugiere que los procesos de gramaticalización son diferentes. El desarrollo del paradigma pronominal prefijante responde al cambio lexema $>$ morfema gramatical, mientras que el desarrollo del paradigma sufijante respondería al cambio diacrónico de una construcción que representa una unidad mayor al lexema, en el cual la construcción entera es reanalizada -siguiendo la perspectiva de Diacronía de las Construcciones Gramaticales (Diachronic Construction Grammar), sobre la historia de las construcciones gramaticales (Barðdal \& Gildea 2015). Un cambio sintáctico puede dar como resultado la conversión de un ítem léxico en un operador gramatical, lo cual, a su vez, tiene grandes implicaciones para el sistema sintáctico en el que el cambio tuvo lugar. En la sección siguiente, se analiza el desarrollo del paradigma sufijante de objeto en paralelo a la gramaticalización de los locativos y direccionales, a partir del reanálisis de la construcción gramatical.

\section{El desarrollo del paradigma sufijante del objeto}

La evolución de los pronombres como morfemas ligados al verbo entre mediados de siglo XIX y principios de siglo Xx no está del todo clara. Sin embargo, a partir de la documentación disponible, podemos asegurar que eran interpretados como objetos sintácticos. La hipótesis que planteamos es que el desarrollo del objeto sufijante está ligado a la gramaticalización de los locativos y direccionales, y que fueron las construcciones 
de verbos seriados (Cvs) asimétricas ${ }^{7}$ los ambientes sintácticos que dieron lugar a este reanálisis, como ocurrió en otras lenguas del mundo (cf. Aikhenvald 2006). Esta gramaticalización conlleva el reanálisis del sujeto sintáctico (y objeto nocional) en la cvs como objeto sintáctico. Este proceso tuvo que haberse iniciado en wichí/weenhayek bastante antes del siglo XIX (especulamos, incluso, que pudo haberse originado en el proto-mataguayo teniendo en cuenta los cognados sintácticos en el resto de las lenguas de la familia). La variedad bermejeña habría evolucionado hacia la regularización del paradigma sufijante en todos los contextos.

\subsection{Etapas de la evolución del sufijo de objeto}

El proceso de reanálisis y gramaticalización se habría dado en cuatro etapas:

Primera etapa. Posiblemente desde el proto-mataguayo: $\left[\left[s_{i}-\mathrm{V}\right]\left[\mathrm{PRO}_{j}\right.\right.$ $\left.\mathrm{V}_{\text {intr(loc/dir) }}\right]$ ]

Basados en la semejanza formal entre la forma libre y la enclítica, el hecho de que en buena parte de las anotaciones de los siglos XIx y xx el complejo pronombre+partícula se anota separado del verbo, y en la posición del objeto entre el verbo y la partícula, especulamos que pudo haber habido una primera etapa en la que en las cvs asimétricas el sujeto del verbo intransitivo de clase cerrada (dependiente), no correferencial con el del verbo inicial de la serie (de clase abierta), se expresaba mediante

7 Sobre construcciones de verbos seriales en wichí, ver Nercesian (2009-2010). 
un pronombre libre: $\left[\left[\mathrm{s}_{i}-\mathrm{V}\right]\left[\mathrm{PRO}_{j} \mathrm{~V}_{\text {intr(loc/dir) }}\right]\right]$. Este argumento funciona como pivote, porque es el sujeto sintáctico del verbo dependiente, pero semánticamente, es el objeto del verbo principal.

En los registros de fines de siglo xIX las formas de segunda persona objeto en posición preverbal y posverbal, aunque parecidas, son disímiles. El prefijo presenta reducción fónica con respecto al pronombre libre ( $a m>a$-); véase (39). En cambio, en posición posverbal seguido de partícula, como en (40) seguido de -e, el objeto es siempre am (idéntico al pronombre libre).

(39) Mataco

Nu-a-ilon-lá

nu-a-ilon-la

1suj-2OBJ-matar-FuT

‘Te mataré’. (Pelleschi 1897: 183)

(40) Mataco

e-Huoc-on-àme

e-Huoc on-ằm-e

2Pos-dueño 3suJ.gritar-2OBJ-LOC

'Te llama tu patrón'. (Lafone Quevedo, 1896a: 357)

El pronombre suele considerarse parte de un complejo con la partícula, e incluso, se ha analizado como un paradigma flexivo de caso. En (41), se cita la declinación del pronombre libre presentado por Pelleschi (1886), en la cual los casos dativo, acusativo y ablativo son la combina- 
ción del pronombre am con una partícula locativa/direccional. Nótese que la segunda persona es idéntica al pronombre personal libre (aquí el nominativo), excepto en el genitivo que es el prefijo de posesión.

(41) Mataco

$1^{\text {a }}$ PERS. SINGULAR

Nom. 'I', noch-lam, nu, no, ni.

Gen. 'Of me', nuch-cá.

Dat. 'To me', núho.

Acc. 'Me', núja, nu.

Abl. 'With me', nújech $2^{\text {a }}$ PERS. SINGULAR

Nom. 'Thou', ám or ham, and á.

Gen. 'Of thee', ach-cá.

Dat. 'To thee', ámu or hamu.

Acc. 'Thee', am $a$ and ái.

Abl. 'With thee', ámech or ámchie.

Segunda etapa. Posiblemente iniciada en el proto-mataguayo durante el período de divergencia entre las lenguas de la familia, o posteriormente y difundida en toda la familia. Habría consistido en el reanálisis del verbo como posposición y de $s$ como o: $\left[\left[s_{i}-\mathrm{V}\right]\left[\mathrm{PRO}_{j} \mathrm{v}_{\text {intr }}(\mathrm{loc} /\right.\right.$ dir $\left.\left.)\right]\right]>\left[\mathrm{s}_{i}-\mathrm{V}\right.$ $\left.\left[\mathrm{o}_{j}-\mathrm{Pp}\right]\right]$.

El verbo dependiente de la cvs se habría reanalizado como posposición aglutinada al pronombre libre, y el pronombre que sintácticamente era sujeto del verbo dependiente, argumento pivote y objeto nocional de la cvs, se habría reanalizado como objeto sintáctico del verbo cabeza de la cvs, ahora convertida en un predicado monoverbal. El reanálisis y la aglutinación habrían hecho emerger la construcción $\left[\mathrm{s}_{i}-\mathrm{v}\left[\mathrm{o}_{j}-\mathrm{Pp}\right]\right]$. 
Especulamos que la posición posverbal del objeto tuvo como modelo el orden de constituyentes vo de los predicados transitivos básicos.

El reanálisis de los verbos locativos/direccionales tuvo que haber ocurrido simultáneamente al reanálisis de s como o, porque la interpretación del pronombre como un objeto sintáctico solo es posible si el verbo ya no funciona como un predicado. Los ejemplos que encontramos en los registros de la segunda mitad del siglo xix parecerían representar una etapa final de este proceso. Como ilustra el ejemplo (42), la posposición locativa ye está ligada al pronombre no y el sufijo de plural gen (actualmente escrito como hen).

\section{(42) Nocten}

Quiotte noyegen noquieuye eñil.

quiotte no-ye-gen no-quieu-ye eñi-l

IMP.ayudar 1OBJ-LOC-PL 1suJ-obedecer-LOC palabra-PL

'Ayudanos para que cumplamos tus palabras'.

(Extracto de traducción del Padre Nuestro al wichí, Massei 1895: 353).

En las descripciones contemporáneas de las lenguas mataguayas encontramos cognados sintácticos del tipo $\left[\mathrm{s}_{i}-\mathrm{V}-\mathrm{O}_{j}-\mathrm{Pp} / \mathrm{APL}\right]$, y la marcación del objeto como prefijo en predicados transitivos básicos, igual que en la variedad pilcomayeña del wichí/weenhayek. Por este motivo, especulamos que este proceso pudo haberse iniciado en el proto-mataguayo o posteriormente y difundido en toda la familia (contamos con poca información al respecto todavía). Los ejemplos (43) y (44) del maká muestran, 
respectivamente, el objeto prefijante en un predicado transitivo básico y el objeto sufijante seguido de un direccional.

(43) Maká

te-tsi-fen

te-tsi-fen

2A-1oвj-ayudar

'Tú me ayudas'. (Gerzenstein 1994: 100)

(44) Maká

ta-yay-y-ii

ła-yay-y-ii

2S-llamar-1P-posp.hacia

'Tú me llamas'. (Gerzenstein 1994: 124)

En nivaĉle, el objeto amalgamado con el sujeto aparece en posición prefijante en un predicado transitivo básico en (45), y el objeto, como sufijo seguido de un benefactivo, en (46).

(45) Nivaĉle

tsi-van

3A.1P-ver

'Él me ve'. (Fabre 2014: 139) 
50 Nercesian, Verónica. 2019. Variación dialectal y diacrónica del objeto pronominal en wichí/weenhayek

(46) Nivaĉle

ts'i-jova'y-e-m

ts'i-jova'y-e-m

1 S-temer-3овJ-BEN

'Yo le tengo miedo'. (Fabre 2014: 139)

En el ejemplo (47) del chorote, un predicado transitivo básico, el objeto es un prefijo, mientras que en (48), el objeto sufijante está seguido del locativo.

(47) Chorote

si-yéen

si-'ye'en

1овј-mirar

'Me mira/mirás'. (Carol 2014 [2012]: 124)

(48) Chorote
A-jlo-ye-ta
wata'a ka ijno-'wa-s-e $e^{8}$
a-jlo-ye-ta
wata'a ka ijno-'wa-s-e
1A-mandar-PFV-IPFV tanto COMP 3S.IRR+ir-2OBJ-PL-DIST

8 Según Carol (2014 [2012]), en chorote, el pronominal está prácticamente fusionado con el sufijo locativo/direccional y la segmentación no siempre es clara, evidencia de que la relación entre el pronominal y la posposición es mayor que entre el primero y la raíz verbal, como en wichí. 


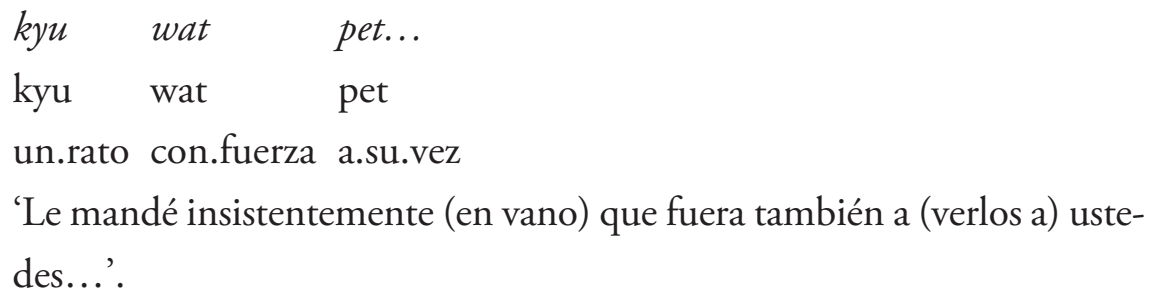

Entonces, si la evolución de las posposiciones por el reanálisis de las cvs ocurrió tal como especulamos para el wichí, es posible que un proceso similar haya ocurrido en el resto de las lenguas de la familia. Por otro lado, observamos que en todas las lenguas mataguayas existen las dos variantes de objeto pronominal: prefijante y sufijante (esta última, en predicados con sufijos/enclíticos/posposiciones locativas y direccionales, además del instrumental/comitativo, y entre la raíz verbal y el locativo/direccional). De modo que, aun no pudiendo precisar por ahora los períodos del proceso de gramaticalización en cada lengua, sí podemos afirmar que es un proceso difundido en toda la familia mataguaya.

Tercera etapa. Desde fines de siglo XIx hasta la actualidad. Habría consistido en la aglutinación y reanálisis de la posposición como aplicativo: $\left[\mathrm{s}_{i}-\mathrm{V}-\mathrm{O}_{j}-\mathrm{APL}_{\mathrm{Loc} / \mathrm{Dir}}\right]_{\text {PRED TR }}$

Como se dijo, la transcripción del complejo pronombre+partícula en los registros del siglo XIX oscila entre una representación fonológicamente independiente y una ligada al verbo principal. En cambio, el pronombre siempre se transcribió ligado a la partícula locativa o direccional (de 
hecho, en más de una fuente se analizó como marca de caso). A principios de siglo xx, Hunt (1940) también presenta oscilaciones en la transcripción de los datos, en algunos predicados separa cada morfema, cf. (19a) y (19b), y en otros, el complejo pronombre+partícula está unido al verbo, pero segmentado con guiones, cf. (20). Más tarde, Lunt (1999) anota el complejo pronombre+partícula separado del verbo; cf. (27) y (37). Mientras que, Viñas Urquiza (1974), Golluscio (1980b), Alvarsson (1984) y Claesson (1994) presentan el complejo pronombre+partícula unido al verbo; cf. (23), (24), (28), (31), (32), (33) y (38).

En consecuencia, no podemos saber si el complejo pronombre+partícula ya era ligado al verbo en el siglo xix. Pero, considerando que la escritura empleada por los misioneros y viajeros intentaba reflejar con la mayor fidelidad posible la lengua, las oscilaciones en la anotación aglutinada o aislante podrían ser indicios de que el proceso de aglutinación se habría iniciado ya en esa época, y que su estatus no se habría estabilizado hasta fines de siglo xx. Además, los registros son de zonas geográficas distintas, de modo que las diferencias en la transcripción también podrían deberse a distintas fases del mismo proceso en cada zona de habla wichí/weenhayek.

El argumento pivote $s$ reanalizado como o es un argumento central en la cvs fuente; probablemente por ese motivo la posposición haya asumido la función de un aplicativo en lugar de seguir el desarrollo de una marca de caso o de una posposición. Y la aglutinación del complejo [o-Pp] al verbo núcleo tal vez se deba a este mismo motivo. En esta etapa, el cambio de la construcción gramatical habría sido $\left[\mathrm{s}_{i}-\mathrm{V}\left[\mathrm{o}_{j}-\mathrm{Pp}\right]\right.$ $>\left[\mathrm{s}_{i}-\mathrm{V}-\mathrm{O}_{j}-\mathrm{APL}_{\mathrm{Loc} / \mathrm{Dir}}\right]$. 
Hay vestigios del funcionamiento de estas partículas como posposición y como aplicativo en Viñas Urquiza (1974), cuyos datos son de Misión Chaqueña (Salta, Argentina). La autora registró alternancias del locativo o direccional añadido a la frase nominal, como en (49a) y (50a), o al verbo, como en (49b) y (50b).

(49) Vejoz
a. tat
le-cho-ye
tat le-cho-ye
IMP.arrojar 3POS-interior-LOC
'Tíralo adentro'. (Viñas Urquiza 1974: 82)

b. tat-e le-cho

tat-e le-cho

IMP.arrojar-LOC 3POS-interior

'Tíralo adentro'. (Viñas Urquiza 1974: 83)

(50) Vejoz

a. naho tektah-e

na-ho tektah-e

HORT-dirigirse río-LOC

'Vayamos al río'. (Viñas Urquiza 1974: 83)

b. naho-je tektah

na-ho-je tektah

HORT-dirigirse-LOC río

'Vayamos al río'. (Viñas Urquiza 1974: 83) 
Existen al menos dos posibilidades: que hacia fines de siglo xx en esa zona existiera esta alternancia y luego se hubiera definido como aplicativo, o que esa alternancia fuera facultativa. Uno de los dos colaboradores principales en la investigación de Viñas Urquiza es hablante trilingüe wichí-chorote-castellano. De modo que existe la posibilidad de que esta alternancia fuera producto de una interferencia del chorote en el habla del colaborador. Cualquiera que sea el caso, parece ser un hecho aislado, puesto que la autora presenta estos ejemplos en una nota de observación en el análisis de la derivación verbal: "NOTA: Este morfema es común al verbo y al adverbio pero son mutuamente excluyentes en una misma oración" (Viñas Urquiza 1974: 82). Por "adverbio" la autora refiere a la frase nominal que funciona como circunstancial de lugar (en 49) o meta (en 50).

La posibilidad de codificar el objeto, no subcategorizado en el verbo, como objeto oblicuo o como objeto aplicado se observa en otras lenguas mataguayas, por ejemplo, el chorote (cf. Carol 2011) y el maká (cf. Gerzenstein 1994), pero no se ha registrado hasta ahora en el wichí reciente, excepto por estos dos ejemplos de Viñas Urquiza. En este sentido, en la evolución de los locativos/direccionales en el grupo mataguayo, el wichí/weenhayek pareciera ser el más alejado de la familia porque los locativos/direccionales y el instrumental se gramaticalizaron como aplicativos (pasando por un estadio de posposición con los pronombres libres), mientras que en chorote y en maká preservan la función de aplicativo y de posposición.

Actualmente, las construcciones wichí con aplicativo se encuentran en las distintas zonas y representarían un estado avanzado del proceso. Los 
ejemplos (51) y (52) son de zonas distintas del pilcomayeño arribeño, (53) es del pilcomayeño abajeño, y (54) y (55) del bermejeño arribeño y abajeño, respectivamente.

(51) Pilcomayo arribeño

Kye 'amel lalotla'noye...

kye 'am-el la-lot-la-'no-ye

CONJ.IRR 2PRO-PL 2sUJ-sentir-FUT-1OBJ-APL

'Cuando ustedes me escuchen...'.

(Nercesian 2012, TC en Tuuntey, Villamontes, Tarija, Bolivia)

(52) Pilcomayo arribeño

Lachufwenn'oyej iyhäj mayhey ta wichi lakeyis.

la-chufwen-n'o-yej iyhäj mayhey ta wichi la-key-is

2suJ-enseñar-1OBJ-APL otro cosas CONJ.R wichí 2POs-costumbre-PL

'Me enseñaron otras cosas sobre las costumbres wichí'.

(Nercesian 2015, TC en Lapacho II, Tartagal, Salta, Argentina)

(53) Pilcomayo abajeño

Otkatay'amho

o-tkatay-'am-ho

1sUJ-cocinar-2OBJ-APL

'Yo cocino para vos'.

(Nercesian 2016, TC en María Cristina, Formosa, Argentina) 
56 Nercesian, Verónica. 2019. Variación dialectal y diacrónica del objeto pronominal en wichí/weenhayek

(54) Bermejo arribeño

n-tox wel-am-ex

n-toxwel-am-ex

1sUJ-conocer-2OBJ-APL

'Te conozco'. (Terraza 2009: 217)

(55) Bermejo abajeño

N'ton'amche.

n'-t'on-'am-che

1sUJ-gritar-2OBJ-APL

‘Te grito/llamo a gritos (te estás alejando)' . (Nercesian 2014 [2011]: 256)

A partir del análisis de Aldridge (2012) del verbo y̌̌ en el chino arcaico tardío como aplicativo, Whitman \& Ono (2017: 46) observan una relación con la transitividad del verbo fuente de la gramaticalización: mientras que las preposiciones tienen como fuente verbos transitivos, las posposiciones tienen, además de los sustantivos relacionales, los verbos intransitivos como fuente. Algunos de esos verbos aún existen en el chino moderno, pero otros, han desaparecido. El reanálisis de los verbos locativos y direccionales que tuvo lugar en wichí responde al tipo de reanálisis que proponen estos autores. El verbo intransitivo de la clase cerrada de la cvs asimétrica es reanalizado como posposición en una primera etapa y como aplicativo, en una segunda etapa. El sujeto sintáctico del verbo intransitivo dependiente, que semánticamente era el objeto del verbo de la clase abierta, es reanalizado como objeto sintáctico. Lo que este reanálisis permite es que la dependencia semántica 
del segundo argumento con el verbo inicial de la serie ahora se exprese sintácticamente.

Cuarta etapa. Probablemente entre mediados del siglo XIx y principios del $\mathrm{xx}$-período de divergencia en el sistema pronominal entre el pilcomayeño y el bermejeño ${ }^{9}$ - se habría iniciado el proceso de regularización del objeto sufijante en todos los contextos sintácticos en la variedad bermejeña.

El ejemplo (56) es un predicado transitivo básico y el ejemplo (57), uno derivado por el aplicativo locativo/asociativo, y en ambos casos el objeto de segunda persona es un sufijo. En la variedad pilcomayeña, en cambio, en predicados transitivos básicos el objeto de segunda persona es un prefijo; cf. (1).

(56) Bermejeño

N'wen'am.

n'-w'en-'am

1suj-ver-2овj

'Te veo'. (Nercesian 2003, base de datos léxica bermejeño)

9 Según los datos de las fuentes, en este período también se habría dado la divergencia en la primera persona sujeto: $n^{\prime} o-\sim n^{\prime} u$ - > $o$ - en el pilcomayeño y $n^{\prime}-$ en el bermejeño. En una etapa temprana, las formas n'o- y n'u-se empleaban en todos los contextos. En una segunda etapa, a mediados de siglo XIx y primera mitad del xx, se registra una variación morfológica condicionada por el contexto fónico. Desde mediados del siglo xx, la divergencia diatópica ya se registra estable en todos los contextos: los grupos pilcomayeños emplean $o$ - (excepto un grupo abajeńo que presenta una distribución estable y aparentemente lexicalizada) y los grupos bermejeños, $n^{\prime}$-. 
(57) Bermejeño

N'yomlhiambu.

n'-yomlhi-'am-hu

1suj-hablar-2OBJ-APL.ASOC

'Te hablo a vos'. (Nercesian 2003, base de datos léxica bermejeño)

El proceso de regularización en la variedad bermejeña debió haberse dado por analogía con las formas incipientes de objeto sufijante en construcciones con locativo y direccional y con la primera persona objeto. En este mismo período podría haberse desarrollado la forma prefijante entre los pilcomayeños, y tal vez nunca (o difundida y abandonada) entre los bermejeños. Necesitamos todavía mayores evidencias para alcanzar alguna especulación al respecto.

\subsection{Evidencias del origen verbal de los aplicativos}

Las evidencias del origen verbal de los aplicativos son importantes para la hipótesis de que el objeto sufijante es resultado del reanálisis de un antiguo sujeto de verbo intransitivo en una Cvs asimétrica. Presentamos aquí al menos tres.

La evidencia más fuerte es válida para un grupo de aplicativos porque sincrónicamente coexisten las raíces de las que posiblemente provienen, que llamamos de Clase II: LOCACIón - hi 'en' ( $i h i$ 'estar en'), -pe 'arriba' (ipe' 'estar sobre'), -(che)fwi 'debajo' (ikfwi 'estar debajo'), -wek 'junto a' (iwek 'estar pegado, en contacto con'); DIRECCIón -pho 'hacia arriba' (ikpho 'ascender, subir'), -cho' 'hacia abajo' (icho' 'descender, quebrarse'), -lafwete 'hacia atrás' (iklafwete 'estar detrás'). Respecto a un segundo gru- 
po de aplicativos, Clase I, no tenemos evidencia directa de su origen verbal (si es que este fuera el caso), pero existiendo pruebas directas del otro grupo, este pudo haber tenido el mismo origen: INSTRUMENTO/COMITATIVO/ASOCIATIVO - ej (? iyej 'estar con'); LOCACIÓN - bu 'adentro', -a 'cerca', -e 'lejos', -ey 'muy lejos', DIRECCIÓN - kwe 'alativo', -che 'en extensión, en movimiento' (?iche 'haber'). Los grupos Clase I y Clase II conforman conjuntos cerrados o paradigmas, y pueden añadirse a raíces verbales sin incrementar la valencia, pero modificando el significado del verbo.

Las raíces verbales que se corresponden con los sufijos de Clase II funcionan como predicados independientes, como en (58), y participan de CVs, como en (59).

(58) Bermejeño abajeño

N'ipe'yel'ataj.

n'-ipe' yel'ataj

1suJ-estar.encima caballo

'Monto un caballo'. (Nercesian 2009, TC en Barrio Viejo, Ing. Juárez, Formosa, Argentina)

(59) Bermejeño abajeño

n'-tha eskwela n-'ipe' bicicleta n'-yhuye uspital

n'-tha eskwela n'-ipe' bicicleta n'-yhuye uspital 1suJ-salir escuela 1suJ-estar.encima bicicleta 1suJ-dirigirse hospital 'Voy de la escuela al hospital en bicicleta'.

(Lit. 'salgo de la escuela, monto la bicicleta, me dirijo hacia el hospital') (Nercesian 2009-2010: 209) 
Es más, sincrónicamente, algunas cvs asimétricas todavía alternan con la variante sintética. En la comunidad Tich'a, en Pozo del Mortero, Formosa (Argentina), registré algunos pocos casos en los que los hablantes ofrecieron las dos posibilidades, la construcción serial y el verbo derivado mediante el aplicativo como variantes aceptables y gramaticales, como se ilustra en (60a) y (60b).

(60) Bermejeño abajeño

a. n'-nay n'-ibi tewukw

n'-nay n'-ihi tewukw

1suj-bañarse 1suj-estar.en río

'Me baño en el río'. (Nercesian 2009-2010: 213)

b. n'nay-hi tewukw

n'-nay-hi tewukw

1suj-bañarse-LOC río

'Me baño en el río'. (Nercesian 2009/2010: 213)

Otra evidencia del origen verbal de los locativos y direccionales es su estatus intermedio entre el morfológico y el sintáctico que presentan actualmente. En Nercesian \& Vidal (2014) se mostró que los aplicativos se comportan como derivativos porque crean verbos con un significado distinto. Un conjunto de raíces está lexicalizado con estos sufijos que cambian el significado de la base, por ejemplo: tachem-a 'agarrar', tachem-hu 'cargar (dentro de algo, se usa para líquidos)', te-kwe 'buscar', t'e-ye 'mirar', t'e-ya 'cuidar', t'os-pe' 'pisar sobre', t'os-[h]i 'pisar en', tun-hi 
'estirar', tun-pho 'levantar'. Además, aumentan la valencia del verbo, es decir, habilitan la adición de un objeto. Según Bybee (1985), cuando las categorías gramaticales tienen un grado de pertinencia ${ }^{10}$ alto al verbo, producen cambios semánticos más grandes y menos predecibles en la raíz verbal; consecuentemente, es más probable que sean lexicalizados. Tal parece ser el caso de este grupo de raíces verbales lexicalizadas con direccionales y locativos. En esa lexicalización, los derivativos mantienen su posición original que es pospuesta a la flexión de objeto.

Los aplicativos, al mismo tiempo, se diferencian de los derivativos en tanto que la modificación de la valencia no provoca el cambio de clase de la raíz verbal como sucede con los causativos. Así, el verbo derivado mediante el aplicativo preserva el prefijo $t(a)$ - de clase intransitiva agentiva, en lugar de cambiar por $i$ - de clase transitiva, a pesar de recibir un objeto (aplicado). Compárense la derivación aplicativa en (61a) y (61b), en la que el verbo mantiene el prefijo $t(a)$-, y la causativa en (61a) y (61c), en la que $t(a)$ - cambia por $i$ -

(61) Bermejeño abajeño

a. $n^{\prime}-t-k a t i n$

$n^{\prime}-t-k a t i n$

1sUJ-CL.VBL.INTR-saltar

'Salto'. (Nercesian 2014 [2011]: 238)

10 "A category is relevant to the verb to the extent that the meaning of the category directly affects the lexical content of the verb stem." [El énfasis en itálica es original] (Bybee 1985: 15). 
b. n'-t-katin-'am-ey

n'-t-katin-'am-ey

1sUJ-CL.VBL.INTR-saltar-2OBJ-APL.LOC

'Yo salto hacia vos (que estás muy lejos)'. (Nercesian y Vidal 2014: 350)

c. i-katih-yen-n'u

$\varnothing$-i-katih-yen-n'u

3SUJ-CL.VBL.TR-saltar-CAUS-1OBJ

'Me hace saltar'. (Nercesian 2014 [2011]: 238)

Finalmente, una tercera evidencia de la procedencia sintáctica de los sufijos locativos y direccionales es la posición que ocupan en la estructura morfológica. A diferencia de cualquier otro sufijo derivativo, los aplicativos ocupan la última posición, incluso en las bases lexicalizadas. Como resultado, el objeto pronominal queda siempre antes del sufijo derivativo, y este último alejado de la raíz que deriva. Obsérvense los ejemplos (62) y (63) que son raíces actualmente lexicalizadas, y (64) que es una raíz no lexicalizada. En (62) el objeto se insertó entre la raíz y el sufijo lexicalizado, y en (63), el causativo, el sufijo de tiempo y el objeto se interponen entre la raíz y el sufijo lexicalizado.

(62) Bermejeño abajeño

n'-t'e...'am...kwe

n'-t.'e<'am>kwe

1suJ-mirar $<2$ OBJ $>$ alativo

'Te busco (por todos lados)'. (Nercesian y Vidal 2014: 350) 
(63) Bermejeño abajeño

$$
\begin{aligned}
& n^{\prime}-t^{\prime} o s-y e n-l a-' a-p e^{\prime} \\
& n^{\prime}-t^{\prime} o s<y e n-l a-' a>p e '
\end{aligned}
$$

1sUJ-pisar<CAUS-FUT-2OBJ>sobre

'Te voy a hacer pisar sobre algo'. (Nercesian 2014 [2011]: 4)

El verbo t’on 'gritar', en (64), está derivado por el aplicativo y el objeto también está interpuesto.

(64) Bermejeño abajeño

$$
\begin{aligned}
& \text { n'-t'on-'am-che } \\
& \text { n'-t'on-'am-che } \\
& \text { 1sUJ-gritar-2OBJ-APL } \\
& \text { 'Te llamo a gritos (estás atravesando a lo largo)'. }
\end{aligned}
$$

(Nercesian 2014 [2011]: 238)

Estos casos en los que se viola el postulado universal propuesto por Bybee (1985) -que predice que los afijos derivativos se encuentran más cerca de la raíz que los flexivos- encuentran su explicación en las fuentes que dieron origen a este tipo de construcciones aglutinantes.

\section{Conclusiones}

La variación geográfica y diacrónica del objeto pronominal es un rasgo que distingue dos complejos dialectales: el pilcomayeńo y el berme- 
jeño. En el pilcomayeño, el objeto es un prefijo en predicados básicos y causativizados, y un sufijo, en predicados con locativos/direccionales; en el bermejeño, el objeto siempre es un sufijo. Esta variación se debe, por un lado, a dos procesos de gramaticalización distintos y, por el otro, a la regularización del paradigma sufijante en el bermejeño. El lapso de un siglo y medio, desde mediados de siglo XIX hasta fines del Xx, parece haber sido el tiempo en que algunos pronombres se gramaticalizaron, $y$ este proceso fue dispar en las distintas zonas de habla wichí. Entre fines del siglo XIx y fines del xx, el objeto prefijante de segunda persona se extendió en el grupo pilcomayeño. En el bermejeño, el objeto pronominal ya se encuentra estable como sufijo a principios de este siglo.

La fuente de gramaticalización y el tipo de proceso de desarrollo de las formas prefijante y sufijante son distintos. La gramaticalización del objeto prefijante responde al cambio lexema>morfema gramatical, el cual sigue las tendencias tipológicas que se correlacionan con el orden de palabras vo. En cambio, el desarrollo de las formas sufijantes en construcciones con locativos/direccionales en ambos grupos dialectales emerge de un proceso de reanálisis de la cvs simultáneo a la gramaticalización de los locativos/direccionales. Este proceso habría ocurrido en cuatro etapas: $1^{\text {a }}$ Posiblemente desde el proto-mataguayo. Construcción de verbos seriados asimétrica con pronombre libre expresando el sujeto del verbo intransitivo de clase cerrada: $\left[\left[\mathrm{s}_{i}-\mathrm{v}\right]\left[\mathrm{PRO}_{j} \mathrm{~V}_{\text {intr(loc/dir })]}\right] .2^{\mathrm{a}}\right.$ Posiblemente iniciada en el proto-mataguayo o posteriomente y difundida en la familia (se hallaron cognados sintácticos en fuentes actuales que sugieren esta hipótesis). Reanálisis del verbo como posposición y de s como o: $\left[\mathrm{s}_{i}-\mathrm{v}\left[\mathrm{o}_{j}-\mathrm{Pp}\right]\right]$. $3^{\text {a }}$ Desde fines de siglo XIx hasta la actualidad. Aglutinación y reanáli- 
sis como aplicativo: $\left[s_{i}-\mathrm{V}_{-} \mathrm{O}_{j}-\mathrm{APL}_{\mathrm{Loc} / \mathrm{Dir}}\right]$ PRED.TR. $4^{\mathrm{a}}$ Probablemente entre mediados del siglo XIx y principios del xx. Regularización del paradigma sufijante en todos los contextos sintácticos en la variedad bermejeña.

Las evidencias del origen verbal de los locativos/direccionales que sostienen la hipótesis de que el objeto sufijante habría sido un sujeto en la cvs (y objeto semántico) reanalizado como objeto sintáctico son al menos tres: a) la coexistencia de raíces cognadas en al menos un grupo (Clase II); b) su estatus intermedio entre morfológico y sintáctico en el wichí contemporáneo, y c) su posición periférica (después del objeto) en la estructura morfológica del verbo.

Este trabajo y el avance del estudio de la variación dialectal y diacrónica en curso amplían la comprensión de la variación y la historia de la lengua wichí/weenhayek, pero también de la familia mataguaya.

\section{Abreviaturas}

$1=$ primera persona, $2=$ segunda persona, $3=$ tercera persona, $A=$ sujeto de verbo transitivo, $\mathrm{APL}=$ aplicativo, $\mathrm{ASOC}=$ asociativo, $\mathrm{BEN}=$ benefactivo, CAUS=causativo, CL.VBL.INTR=clase verbal intransitiva, CL.VBL.TR=clase verbal transitiva, $C O M P=$ complementante, $C O N J . I R R=$ conjunción de irrealis, CONJ.R=conjunción de realis, $\mathrm{CvS}=$ construcción de verbos seriales, DIR=direccional, DIST=distal, FUT=futuro, HORT=hortativo, IMP=imperativo, $I N T E R R=$ interrogativo, $I P F V=$ imperfectivo, $I R R=$ irrealis, LOC=locativo, $\mathrm{NEG}=$ negativo, $\mathrm{OBJ}=$ objeto, $\mathrm{P}=$ paciente, $\mathrm{PFV}=$ perfectivo, $\mathrm{PL}=$ plural, 
POS=poseedor, $\mathrm{POSP}=$ posposición, $\mathrm{PRO}=$ pronombre libre, $\mathrm{PROH}=$ prohibitivo, $\mathrm{S}=$ sujeto de verbo intransitivo, suJ=sujeto.

\section{Agradecimientos}

Agradezco a Spike Gildea los comentarios a las ideas preliminares del trabajo, a Bernard Comrie la lectura de una versión de este artículo y sus valiosas observaciones, y a los dictaminadores por sus comentarios y sugerencias. Esta investigación se realizó en el marco de los Proyectos PICT 2013-2539 Estudio de la variación dialectal de la lengua wichí/ weenhayek (mataguaya) del Chaco boreal (Argentina y Bolivia) у Ріст 2016-0593 Lengua y territorio wichí/weenhayek (mataguayo): isoglosas, variedades dialectales y procesos sociohistóricos en el norte de Argentina y sur de Bolivia, financiados por el fOnCYT, AGEncia, Ministerio de Ciencia, Tecnología e Innovación Productiva, Argentina.

\section{REFERENCIAS}

Aikhenvald, Alexandra. 2006. Serial verb constructions in typological perspective. En Aikhenvald, Alexandra \& Dixon, R.M.W. (eds.), Serial verb constructions: A cross-linguistic typology, 1-68. Cambridge: Cambridge University Press.

Aldridge, Edith. 2012. PPs and applicatives in late Archaic Chinese. Studies in Chinese linguistics 33(3).139-164. 
Alvarsson, Jan-Ake. 1979. Wee'hnayek lhamet. Un manual del idioma mataco-noctenes. Cochabamba: Imprenta indigenista boliviana. Alvarsson, Jan-Ake. 1984. Weenhayek lhamet. Cochabamba: Misión Sueca Libre.

Barðdal, Jóhanna \& Gildea, Spike. 2015. Epistemological context, basic assumptions and historical implications. En Barðdal, Johanna \& Smirnova, Elena \& Sommerer, Lotte \& Gildea, Spike (eds.), Diachronic construction grammar, 1-50. Amsterdam: John Benjamins Publishing Company.

Bybee, Joan L. 1985. Morphology: A study of the relation between meaning and form. Amsterdam: John Benjamins Publishing Company.

Carol, Javier J. 2011. Aplicativos/adposiciones en chorote (mataguayo): algunos aspectos formales. LIAMES: Linguas Indígenas Americanas 11(1). 51-74. Dor: doi.org/10.20396/liames.v0i11.1496

Carol, Javier J. 2014 [2012]. Lengua chorote (mataguayo). Estudio fonológico y morfosintáctico (Studies in Native American Linguistics 72). Múnich: Lincom Europa.

Claesson, Kenneth. 1994. A phonological outline of mataco-noctenes. International journal of American Linguistics 60(1). 1-38.

d'Orbigny, Alcide. 1896. Vocabulario y apuntes. Dialecto Vejoz. Boletín del Instituto Geográfico Argentino xvII (4 6). 121-176. La Plata: Instituto Geográfico Argentino.

Dryer, Matthew S. 2013a. Prefixing vs. suffixing in inflectional morphology. En Dryer, Matthew S. \& Haspelmath, Martin (eds.), The world atlas of language structures online. Leipzig: Max Planck Institu- 
te for Evolutionary Anthropology. http://wals.info/chapter/26 (Consultado el 15-10-2018.)

Dryer, Matthew S. 2013b. Order of object and verb. En Dryer, Matthew S. \& Haspelmath, Martin (eds.), The world atlas of language structures online. Leipzig: Max Planck Institute for Evolutionary Anthropology. http://wals.info/chapter/83 (Consultado el 15-10-2018.)

Equipo técnico de la UBA \& equipo de MEMAs. 2003. Gramática escolar de la lengua wichi. Formosa: Subprograma de Educación y Programa de Desarrollo Integral Ramón Lista).

Fabre, Alain. 2014. Estudio gramatical de la lengua Nivacle. Kangasala: Finlandia. (Edición provisional disponible en línea en http://www. etnolinguistica.org/biblio:fabre-2014-estudio).

Gerzenstein, Ana. 1978. Lengua chorote I. Buenos Aires: Universidad de Buenos Aires.

Gerzenstein, Ana. 1992. Una variedad oriental del mataco. En Braunstein, José (comp.), Hacia una nueva carta étnica del Gran Chaco: informe de avance IV, 67-79. Formosa: Centro del Hombre Antiquo Chaqueño (Chaco).

Gerzenstein, Ana. 1994. Lengua maká. Estudio descriptivo. Buenos Aires: Universidad de Buenos Aires.

Gerzenstein, Ana. 2003. Variaciones dialectales de algunas unidades del sistema consonántico wichí. En Tissera, Alicia \& Zigarán, Julia (comps.), Lenguas y culturas en contacto, 69-81. Salta: CEPIHA-Universidad Nacional de Salta.

Gildea, Spike. 2002. Pre-proto-tupí-guaraní main clause person-marking. En Arruda Câmara Cabral, Ana Suelly \& Rodrigues, Aryon 
Dall'Igna (orgs.), Linguas indigenas brasileiras. Fonologia, gramática e histórica. Actas do I encontro internacional do grupo de trabalho sobre línguas indigenas da ANPOLL, 315-326. Belém/Pará: Editora Universitária UFPA.

Golluscio, Lucía. 1980a. Descripción del núcleo gramatical de la lengua wichí (mataco), Variedad hablada en el Teuco (El Sauzalito, Chaco y zona de influencia). Informe de avance. Consejo Nacional de Investigaciones Científicas y Técnicas. MS.

Golluscio, Lucía. 1980b. Lista de emisiones elicitada del español al wichí en Sauzalito. Material de Archivo.

Golluscio, Lucía. 1993a. Clases de sustantivos y sistema cultural: la posesión en wichí. Signo y Seña 3. 219-239.

Golluscio, Lucía. 1993b. Deixis in wichí. (Ponencia presentada en el Congreso de Society for the Study of Indigenous Languages of the Americas, American Anthropological Association, Washington, DC, 17-21 de noviembre de 1993.)

Greenberg, Joseph. 1963. Some universals of grammar with particular reference to the order of meaningful elements. En Greenberg, Joseph (ed.), Universals of grammar, 73-113. Londres: MIT Press.

Harrington, John P. 1948. Matako of the Gran Chaco. International Journal of American Linguistics, 14(1). 25-28.

Hunt, Richard. 1913. El vejoz o aiyo. Revista del Museo de La Plata, 22. 6215.

Hunt, Richard. 1937. Mataco-english and english-mataco dictionary (with grammatical notes). En Ethnological Studies 5, Kaudern; Walter (ed.). Gotemburgo: Ethnographical Museum. 
Hunt, Richard. 1940. Mataco grammar. Tucumán: Instituto de Antropología y Universidad Nacional de Tucumán.

Lafone Quevedo, Samuel A. 1895. Introducción y notas. Grupo mataco-mataguayo del Chaco. Dialecto noctén por Inocencio Massei. Boletín del Instituto Geográfico Argentino. XVI. (9-12). 343-390. Buenos Aires: Instituto Geográfico Argentino.

Lafone Quevedo, Samuel A. 1896a. Prólogo y vocabulario comentado. Los indios matacos y su lengua por Joaquín Remedi. Boletin del Instituto Geográfico Argentino. XVII.Cuadernos?.331-362. Buenos Aires: Instituto Geográfico Argentino.

Lafone Quevedo, Samuel A. 1896b. Introducción, notas y comentarios. Grupo mataco-mataguayo del Chaco. Dialecto vejoz. Con vocabulario y apuntes de d'Orbigny. Boletín del Instituto Geográfico Argentino. XVII(46). 121-176. Buenos Aires: Instituto Geográfico Argentino.

Lafone Quevedo, Samuel A. 1897. Introducción y notas. Los indios mataguayos y su lengua por Giovanni Pelleschi. Boletin del Instituto Geográfico Argentino. XVIII (4 6). 173-350. Buenos Aires: Instituto Geográfico Argentino.

Lehmann-Nitsche, Robert. 1910-1911. Vocabulario chorote ó solote (chaco occidental). Revista del Museo de La Plata17. 111-130.

Lunt, Roberto. 1999. Wichi Lhämtes. Salta: Hanne.

Massei, Inocencio. 1895. Dialecto noctén. Boletín del Instituto Geográfico Argentino. XVI (9-12). 343-390. Buenos Aires: Instituto Geográfico Argentino.

Messineo, Cristina \& Braunstein, José. 1990. Variaciones lingüísticas del mataco. Hacia una nueva carta étnica del Gran Chaco I. Informe 
de avance. 1-13. Formosa: Centro del Hombre Antiquo Chaqueño (Chaco).

Mithun, Marianne. 2003. Why prefixes? Acta linguistica hungarica 50(12). 155-185.

Najlis, Elena. 1968. Dialectos del mataco. Anales de la Universidad del Salvador 4. 232-241. Buenos Aires: Universidad de Buenos Aires.

Nercesian, Verónica. 2007. Retracción y recuperación lingüística: el caso de un migrante wichí. Signo y Seña 17. 163-192.

Nercesian, Verónica. 2009-2010. Construcciones de verbos seriales en wichí (mataguaya). Características sintácticas y semánticas. Amerindia 33-34: 187-216.

Nercesian, Verónica. 2013. Bases lingüísticas y sociohistóricas del estudio dialectal del wichí/weenhayek. (Ponencia presentada en el VII Bolivian Studies Association International Congress/2013. Sucre, Bolivia, 29 de julio-1 de agosto de 2013).

Nercesian, Verónica. 2014 [2011]. Wichi lhomtes. Estudio de la gramática y la interacción fonología-morfología-sintaxis-semántica. Múnich: LINCOM.

Nercesian, Verónica \& Vidal, Alejandra. 2014. Operaciones de aumento de valencia y clases verbales en wichí (mataguaya). En Queixalós, Francesc \& Telles, Stella \& Bruno, Ana Carla. (eds.), Mudanças incremenciais de valência nas lenguas amazônicas, 329-354. Bogotá: Instituto Caro y Cuervo/Universidad Nacional de Colombia.

Pelleschi, Giovanni. 1886. Eight months on the Gran Chaco of the Argentine republic. Londres: Sampson Low, Marston, Searle, \& Rivington. 
Pelleschi, Giovanni. 1897. Los indios mataguayos y su lengua (con nota de Lafone Quevedo). Boletín del Instituto Geográfico Argentino XVIII(46). 173-350. Buenos Aires: Instituto Geográfico Argentino.

Remedi, Joaquín. 1896. Los indios matacos y su lengua. Con vocabulario ordenado por Lafone Quevedo. Boletín del Instituto Geográfico Argentino. Tirada Aparte. Buenos Aires: Instituto Geográfico Argentino. Stell, Nélida. 1987. Gramática descriptiva de la lengua nivacle (chulupi). Buenos Aires: Universidad de Buenos Aires. (Tesis Doctoral.)

Terraza, Jimena. 2009. Grammaire du wichi: Phonologie et morphosyntaxe. Québec: Universidad de Québec. (Tesis Doctoral.)

Tovar, Antonio. 1961. Catálogo de lenguas de América del Sur. Buenos Aires: Sudamericana.

Tovar, Antonio. 1964. El grupo mataco y su relación con otras lenguas de América del Sur. Actas del $35^{a}$ Congreso internacional de americanistas II. 439-452.

Tovar, Antonio. 1981. Relatos y diálogos de los matacos. Madrid: Ediciones Cultura Hispánica del Instituto de Cooperación Iberoamericana. Vennemann, Theo. 1973. Explanation in syntax. En Kimball, John P. (ed.), Syntax and semantics 2, 1-50. Nueva York: Seminar Press.

Vidal, Alejandra \& Nercesian, Verónica. 2005a. Sustantivo y verbo en wichí. Hacia una taxonomía de clases de palabras. Liames 5. 7-25.

Vidal, Alejandra \& Nercesian, Verónica. 2005b. Causativos en wichí (mataco-mataguaya). Proceedings of the Conference on Indigenous Languages of Latin America-II. http://www.ailla.utexas.org/site/cilla2_ toc.html. 
Vidal, Alejandra \& Nercesian, Verónica. (En prensa). Body-parts and possessive constructions in Mataguayan languages. En Valenzuela, Pilar \& Zariquiey Biondi, Roberto (eds.), The grammar of body-part expressions: A view from the Americas. Oxford: Oxford University Press. Vidal, Alejandra \& Payne, Doris. (En prensa). Polyfunctional vankain Nivaĉle: Antipassive, middle, and beyond. En Janic, Katarzyna \& Witzlack-Makarevich, Alena (eds.), The multifaceted aspects of Antipassive. Amsterdam: John Benjamins.

Viñas Urquiza, María Teresa. 1974. Lengua mataca Iy II. Buenos Aires: Centro de Estudios Lingüísticos.

Whitman, John \& Ono, Yohei. 2017. Diachronic interpretations of word order parameter cohesion. En Mathieu, Éric \& Truswell, Rober$\mathrm{t}(\mathrm{eds}$.$) , Micro-change \& macro-change in diachronic syntax, 43-60.$ Oxford: Oxford University Press. 